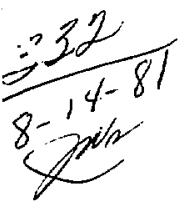

(1) 012944 $\beta 6433$

\title{
An Analysis of the "Mine-By" Experiment, Climax Granite, Nevada Test Site
}

Francois E. Heuze MASTER Theodore R. Butkovich John C. Peterson

June 1981

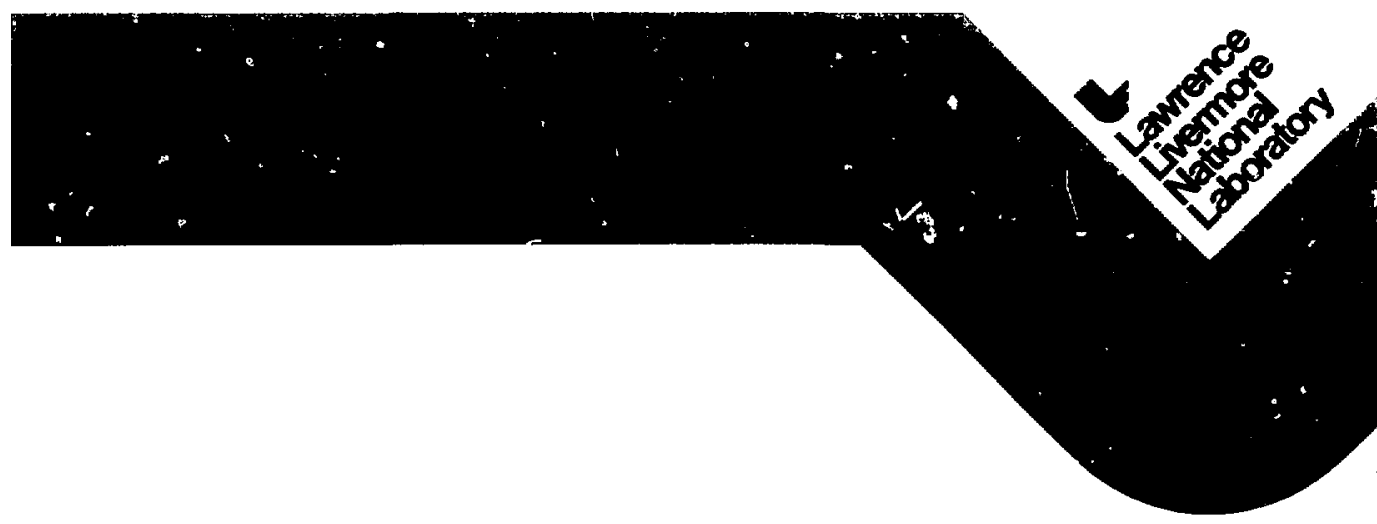


I!CRI,-S:133

Distribution Category LC:-70

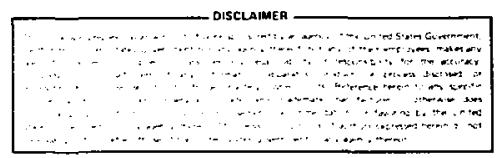

\title{
An Analysis of the "Mine-By" Experiment, Climax Granite, Nevada Test Site
}

\author{
Francois E. Heuze \\ Theodore R. Butkovich \\ John C. Peterson
}

Manuscript date: June 1981

\section{LAWRENCE LIVERMORE LABORATORY} University of California $\bullet$ Livermore, California 994550 


\section{FOREWORD}

This work was supported under the Department of Energy's National Waste Terminal storage Program. It was adainistered through the Nevada Operations Office, as part of the Spent Fuel Test Climax (SFT-C), at the Nevada Test Site.

Ms. D. Olson and Ms. L. Burrow typed the manuscript. Their assistance is gratefuily acknowledged. 


\section{AN MHALYSIS OF THE "MTNE-BY* \\ EXPERIMENT, CLIMAX GRANITE, \\ NEJADA TEST STTE}

ABSTRACT

An analysis of the mine-by at SFT-C was performed by means of refined finite element models using the JPIAXD code (jointed, PLare and Axisymetric, Dilatant). The input for the new models was derived from our field program, which is reported separately. In sumary:

- Onlike the stress results obtained with previous models, the vertical pillar stresses calculated with JPIAXD are consistent with the field observations from VsM stress gages. This consistency covers calculations for the stress relief due to blasting, in the skin of the pillars, and for localized stress decreases due to joint patterns, in the core of the pillars.

- Notwlthstanding the above local decreases, all calculations show that the mean vertical stress increases in both pillars, during the mine-by.

- A set of rock mass shear strength paraneters was selected by successive trials to indicate only minor damage around the caverns and in the pillars, during mining. This selection is consistent with the field observations; it is also consistent with expected increases in average vertical pillar stress during mining, when pillars do not fail.

- Hence, the shear strength values from the JPLAXD models can be used as a lower-bound estimate of the in situ strength of the climax granite.

- The multi-position extensometer (MPE) movements predicted by the new analysts are generally higher than those predicted by former models. This was to be expected, because previous models used modulus values derived from laboratory tests, whereas the JPIAXD calculations use modulus values obtained in situ. Neither calculation is well matched by data reported fron the field.

- N.ll models show that, during mining of the center drift, all caverns close vertically, ard the center drift closes horizontally. The walls of the two heater drifts move toward the center drift, with a siight opening or a slight closing of the heater drifts, depending ipon the geology.

- All calculations show both pillars expanding laterally during mine-by. 
- The field-reported Iateral contraction of the pillars leads to the very suspicious conclusion that the pillars end up in a state of tension.

- The fleld-reported values from horizontal MPEs and horizontal tapes appear to be inconsistent with each other.

While the reported changes in vertical pillar stress have been explained, no explanation was found for the deformation patterns reported from horizontal MPEs and tapes. Both the former and the new rodels give consistent patterns of deformations in and around the pillars. This casts some doubts on the validity of the horizontal fleld deformation data, which appear not to be consistent with the reported changes in pillar stress. On the other hand, it seems that the combination of the in situ geomechanics performed at SFT-C and the new models provides a coherent representation of the climax mine-by. 


\section{INTRODUCTION: THE SPENT FUGL TEST AT CLIMAX (SFT-C)}

The Lawrence Livermore National Laboratory (LWWL) is conducting a generic test of retrievable geologic storage of nuclear spent fuel assemblies, in an underground chamber, at the Nevada Test site, Nye County, Nevada. ${ }^{1,2}$ This gener ic test is located $420 \mathrm{~m}$ below the surface, in the climax granitic stock. Eleven canisters of spent fuel approximately 2.5 years out of reactor core (about $1.6 \mathrm{kN} / \mathrm{canister}$ thermal output) are now emplaced in a storage arift, along with 6 electrical heaters which simulate fuel canisters. Two adjacent drifts contain other electrical heaters, which will be operated to simulate the thermal field of a large repository. The three arifts are shown in plan view in Fig. 1.

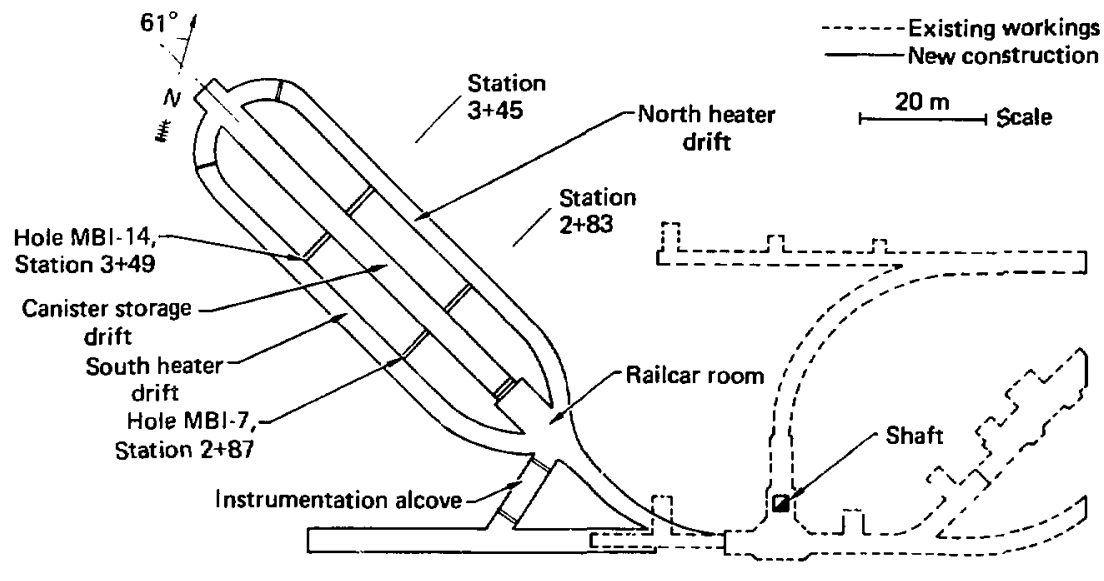

FIG. 1. Spent Fuel Test layout in the climax granite, Nevada Test site. 
The climax stock, at the Nevada Test site, is composed of quartz monzonite and granodiorite. ${ }^{3}$ The spent Fuel Test-Climax (SFT-C) is located in the quartz monzonite, which contains three sets of joints nearly perpendicular to each other:

\begin{tabular}{lll} 
& $\begin{array}{c}\text { Average } \\
\text { strike }\end{array}$ & \multicolumn{1}{c}{$\begin{array}{c}\text { Aver age } \\
\text { dip }\end{array}$} \\
Joint set 1 & N32 & N2NE \\
Joint set 2 & N64 & Near vertical \\
Joint set 3 & N35 E & Near vertical
\end{tabular}

In addition, there are a number of shears intersecting the three chambers.

\section{THE MINE-BY EXPERIMENT AT SFT-C}

The excavation was performed in three steps: the two heater drifts were excavated first, then the top heading of the canister drift was mined, and finally, the bench was removed. Before the mine-by of the center (canister) drift, deformation and stress gages were emplaced fram the heater drifts near two locations labeled stations $2+83$ and $3+45$ in Fig. 1 . A schematic of the instrument arrays is shown in Fig. 2.

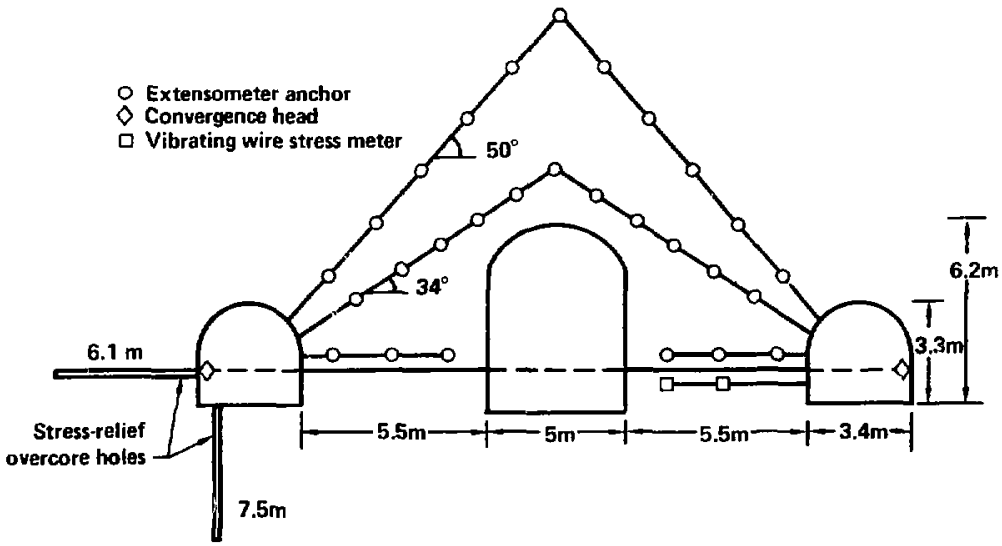

FIG. 2. Idealized cross section of the Spent Fuel Test drifts. 


\subsection{MINE-BY DATA FOR DEFORMATIONS AND STRESSES}

The relative displacements, due to the mine-by, between the anchors and the sensing heads of the 12 multi-position extensometers are shown in Fig. 3. The numbers in parentheses are values calculated from previous elastic and isotropic finite element models using the ADINA code. 2,4 Figure 4 shows the layout of convergence stations in the center drift. Figure 5 and Table 1 show the deformations in the horizontal direction, both from the horizontal MPEs and from tape measurements across the arifts. Such measurements were made possible across the full width of the site (points A to F in Fig. 5), because of two NX holes drilled between points $B$ and $E$, at stations $2+87$ and $3+49$, before the center drift was mined.

The only stress data obtained during the mine-by were stress changes in three vibrating wire stressmeters (USMs) installed in the north pillar. 2,5 TwC VSMs were at station $2+80$ and one at station $3+02$. Only one of them (VSM-2) was in the center of the pillar. The VSM data for vertical pillar stress changes due to the mine-by are shown in Table 2, where they are compared to calculations from the ADINA model mentioned above.

\subsection{PREVIOUS COMPARISON OF FIELD DATA AND MODES CALCULATIONS}

Prior to this new analysis, two series of models were applied to the mine-by. Before mine-by, LINL performed scoping calculations with the ADINA code. $^{2}$ After the mine-by, Terra-Tek Inc. performed calculations with the TWODI (finite element) and the DIG (boundary element) codes. ${ }^{6}$ The results of the three calculations were similar, which was to be expected because of the similarity of the input. None of the above models explicitly included the geological discontinulties, such as joints and shears. The rock mass modulus was taken from handbook values, since no field estimates had been obtained, at that time. In the ADINA calculations ${ }^{2}$ the ratio of horizontal to vertical stress was varied between 0.8 and 1.0. In the DIG and TwODI calculations ${ }^{6}$ the ratio varied between 0.8 and 1.25 . The highest value, 1.25 , is close to that derived from the analysis of overcoring measurements made by the U.S. Geological survey around the south heater drift, 7 sone of these models could represent strain-softening or dilatancy of the rock mass in the post-peak condition. 


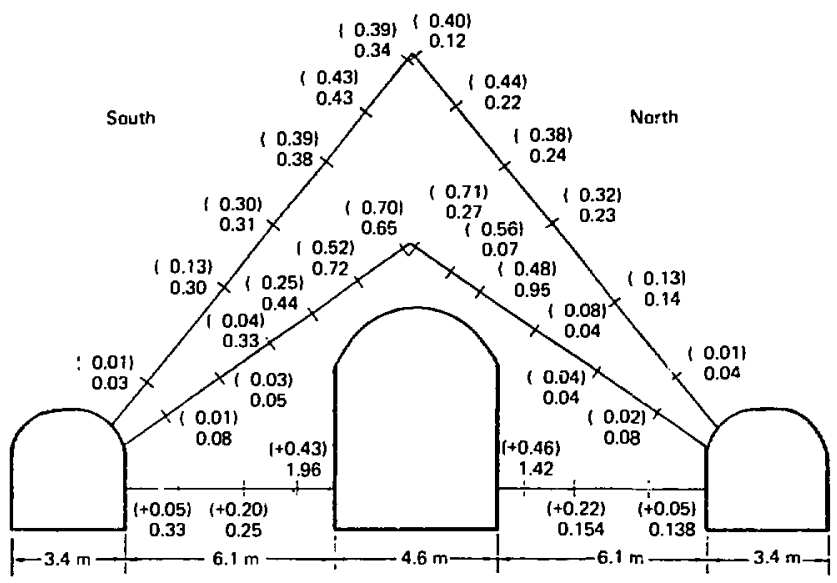

(a) Station $2+83$

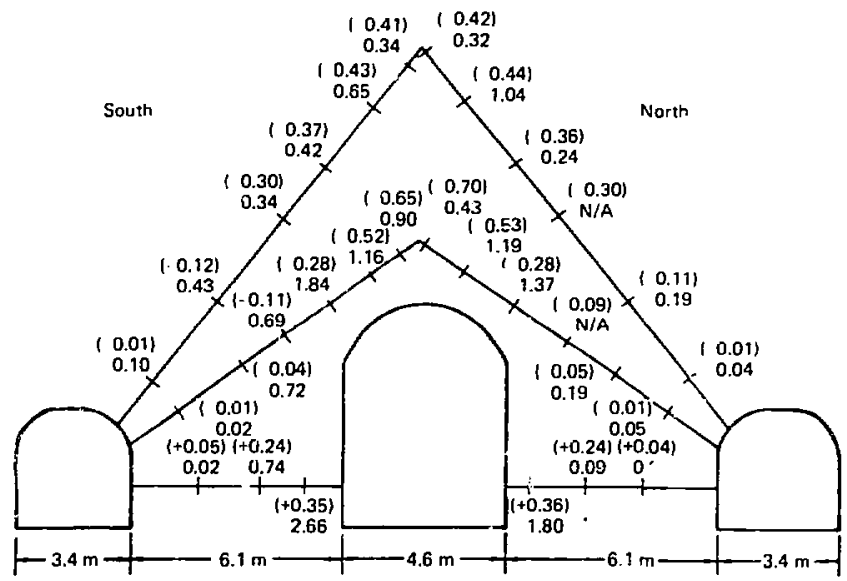

(b) Station 3+45

FIG. 3. Comparison of observed and (ADINA-calculated) displacements (mn) during mine-by. ${ }^{2}$ Minus sign indicates shortening; plus sign indicates lengthening. 


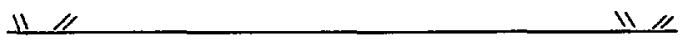

South Heater Drift

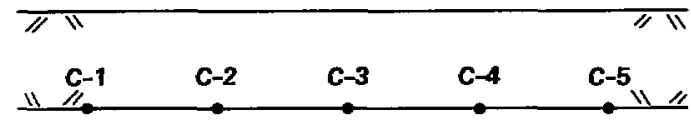

Center (Canister) Drift

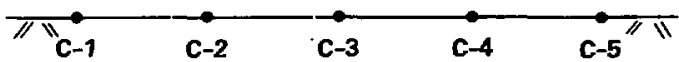

111

1111

North Heater Drift

$2+83+45$

FIG. 4. Layout of horizontal tape station in the center drift.
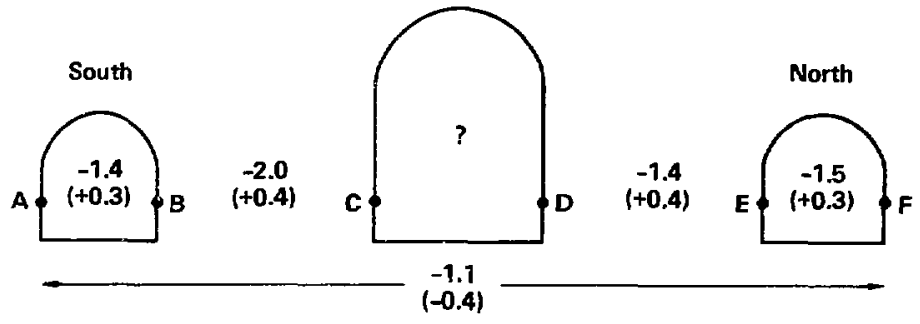

$(-0.4)$
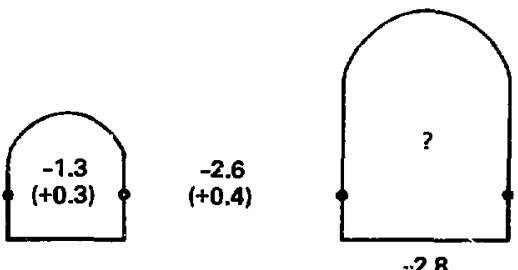

$-1.8$

$(+0.4)$

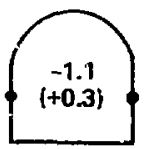

$-2.8$

$(-0.4)$

FIG. 5. Comparison of observed and (ADINA-calculated) horizontal movements (mim) across the three caverns, due to the mine-by. Pillar deformation values are from MPEs. Other values are from tapes. Top: Station 2+87. Bottom: station $3+45$. 
TABIE 1. Results of convergence/dtvergence readings (min) ${ }^{\star}$, ili the center drift. 6

\section{Mining}

\begin{tabular}{|c|c|c|c|c|c|c|c|c|c|}
\hline \multirow[b]{2}{*}{ station } & \multicolumn{3}{|c|}{ Top heading } & \multicolumn{6}{|c|}{ Bench } \\
\hline & $3+77$ & $3+95$ & $2+05$ & $2+3.3$ & $2+59$ & $2+72$ & $3+00$ & $3+24$ & $3+60$ \\
\hline \multirow[t]{2}{*}{$c-1$} & & & 0 & 0.17 & & & $0^{\dagger}$ & -1.27 & -0.88 \\
\hline & & & & -0.10 & & & & & \\
\hline \multirow[t]{2}{*}{$\mathrm{C}-2$} & 0 & 0.07 & 0.07 & 0.09 & & -0.13 & & $0^{\dagger}$ & 0.08 \\
\hline & 0.11 & & & & & & & & \\
\hline \multirow[t]{2}{*}{$c-3$} & & & 0 & 0.01 & 1.12 & 0.83 & & $0^{\dagger}$ & 0.08 \\
\hline & & & & -0.16 & & & & -0.13 & \\
\hline \multirow[t]{2}{*}{$c-4$} & & & $a$ & 0.05 & & & $0^{\dagger}$ & 0.71 & 2.65 \\
\hline & & & & 0.08 & & & -0.42 & 0.59 & \\
\hline \multirow[t]{2}{*}{$c-5$} & & & 0 & $C .0 \bar{i}$ & 0.03 & -1.35 & -1.39 & -2.97 & -3.23 \\
\hline & & & & & & $-1.35^{\circ}$ & -1.38 & -2.95 & \\
\hline
\end{tabular}

*Numior increases: divergence. Number decreases: convergence.

$\dagger_{\text {Anchor replaced, new zero. }}$

Anchor replaced, same zero.

TABLE 2. Comparison of measured and calculated vertical stress changes, as a rosult of the mine-by. 2

\begin{tabular}{lcccc}
\hline $\begin{array}{l}\text { Stress } \\
\text { meter }\end{array}$ & $\begin{array}{c}\text { Station } \\
\text { (Fig.1) }\end{array}$ & $\begin{array}{c}\text { canister } \\
\text { drift (m) }\end{array}$ & $\begin{array}{c}\text { vSM }^{\mathrm{a}} \\
\text { reading } \\
\text { (MPa) }\end{array}$ & $\begin{array}{c}\text { Calculated } \\
\text { stress change } \\
\text { (MPa) }\end{array}$ \\
\hline VSM 1 & $2+80$ & 1.0 & -9.7 & +5.1 \\
VSM 2 & $2+80$ & 3.0 & -1.3 & +2.3 \\
VSM 3 & $3+02$ & 1.0 & -7.0 & +5.1 \\
\hline
\end{tabular}

a Vibrating wire stressmeter (VSM) calculations assumed a rock modulus of $61 \mathrm{GPa}$. Minus sign indicates a decrease in compression.

b Rock modulus assumed at $61 \mathrm{GPa}$. Horizontal to vertical stress ratio taken as 0.8 . 
The results of the above modeling can he sumarized as follows:

- The models did not show a reduction in vertical stresses in the pillars during mine-by of the canister arift, as reforted from the field, ${ }^{2,6}$

- The models did not show a horizontal contriction of the pillars during mine-by, as reported from the field. ${ }^{2,6}$

- The relative movements of anchors tor the extensometers at $34^{\circ}$ to the horizontal generally were several times larger than the relative movenients calculated with ADINA.

- The relative movements of anchors frull the extensometers at $50^{\circ}$ to the horizontal were in slightly better agreement with the predicted values.

- An attempt at correlating the pattern of inclined MPE data with local shears fared bet'er in the Nort!, millar than in the south pil:ar. 17

In the previous reports, ${ }^{2,6}$ th: MPE data were considered together with the USM stress change data. Some tape data also were reported, but they s gre judged preliminary, ${ }^{2}$ or unreliable. ${ }^{6}$ the decrease in ver!ical pillar stress and the horizontal contraction of the pillars were hypothesized to be due to stress arching over the caverns. However, this arching hypothesis was not substantiated.

\subsection{DISCUSSION}

The question of the shanges in vertical pillar stresses is addressed first. Although ADINA results shr,ed a stress increase for VSM-I and VSM-3, a stress decrease can easily be ejplained and modeled. ADINä calculations did not include a zone of rock zoftened by b].asting and stress $\iota$ elief around the center drift. The calculations with the JPIAX finite element progran do include the softened zone, and, indzed, they predict a vertical stress decrease at the locations of VSM-1 and VSM-3. As for VSM-2, the JPLAXD models also show that localized stress decrease can take flane in the pillars, depending upon the geometry of the joints and shears. There dues not seem to remain any major guestion related to the stress cuange data from the field, in spite of the scarcity of stress gages. 
The only ridale is the pattern of horizontal movements reported from the field. The data came from two sets of instruments: the horizonial upes in the two pillars, and the tape stations. Pigure 5 shows the MPE data across the width of the pillars, and the tape data, ercept for the stations in the center drift. These last readings were sumarized in Table 1 . It is clear that the records from stations $c-1$ to $c-5$ are somewhat erratic. At all stations, the data mix convergence and divergence, for no apparent reason.

It is easily shown that the ADINA results are at least internally consiste.st, even if their absolute values are questionable because the estimate of modulus for the in-place climax granite was obtained from tests on small cores. 2.9 This procedure disregarded the effeces of scale. ${ }^{10}$ A simple model for the calculated movements of points $A$ to $F$ is:

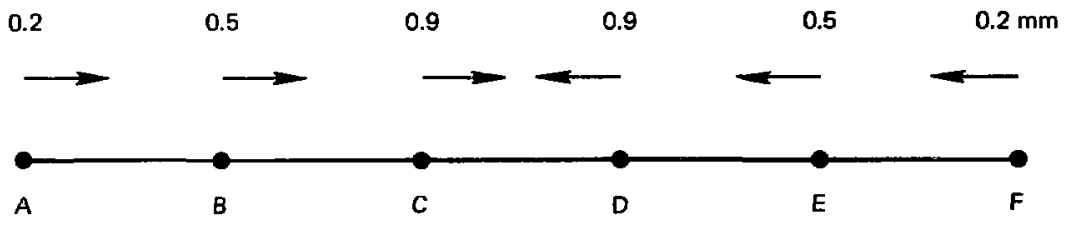

No such models could be constructed to explain the data reported from the field, unless one is prepared to accept that the center dri:t widened upon mine-by. This behavior was not observed in a JPLAXD elastic isotropic calculation where the horizontal to vertical stress ratio was varied between 0.5 and 3.5. Such widening also would be contrary to mining experience.

As for the arching argument, it would imply that the pillars unloaded through some load redistribution on the abutments. The lack of stress gages in the abutments prevents confirmation of this conclusion. Whatever truly happened, the horizontal shortening of the pillars can take place only through one of three modes (Fig.6):

- Unloading before peak.

- Unloading post peak.

- Off-loading in a so-called class-II behavior, only, because class-I off-loading gives a strain increase.

There is no published evidence that the class-II off-loading observed in laboratory compression tests with servo-controlled machines ${ }^{11}$ can exist in 


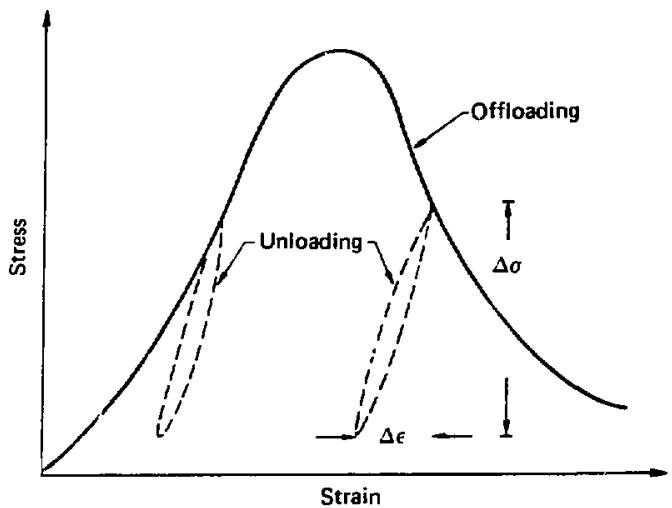

Class I strain-softening

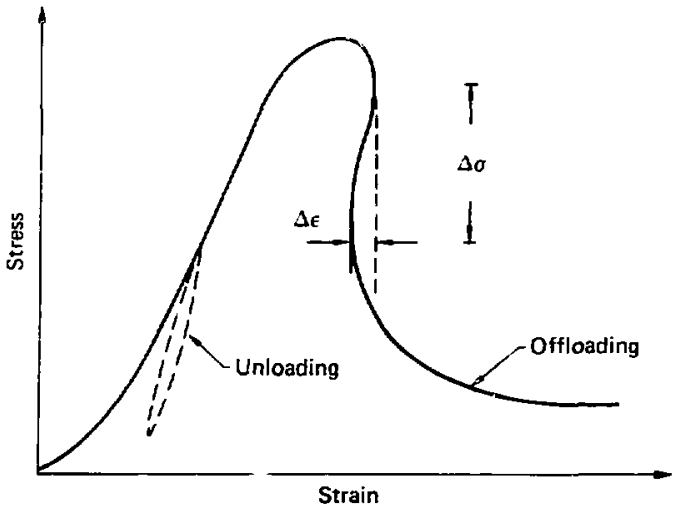

Class II strain-softening

FIG. 6. Strain-softening of rock materials.

the fleld, where the vertical loading is passive, due to the overlying rock. As for the unloading assumption, a simple calculation shows the strange conclusion it leads to. The average of horizontal pillar shrinkage at four locations (Fig. 3) is at least

$$
(1.96+1.42+2.66+1.80) / 4=1.86 \mathrm{~mm} .
$$


For pillars with an average width of $5.5 \mathrm{~m}$ this shrinkage corresponds to a hor izontal unloading strain recovery:

$$
\Delta \varepsilon_{\text {hor }}=1.86 \times 10^{-3} / 5.5
$$

A Polsson's ratio $v=0.246$, obtained in our field progran, ${ }^{12}$ aives s vertical strain recovery:

$$
\Delta \varepsilon_{\text {vert }}=\Delta \varepsilon_{\text {hor }} / 0.246=1.4 \times 10^{-3} \text {. }
$$

From our best estimate of $26 \mathrm{GPa}$ for the in situ nodulus of the Climax granite, ${ }^{12}$ the above $\Delta \varepsilon_{\text {vert }}$ would require a vertical stress relief equal to:

$$
\Delta \sigma_{\text {vert }}=26 \times 10^{3} \times \Delta \epsilon_{\text {vert }}=36 \mathrm{MPa} .
$$

Adnittedly, the pillars start out in a triaxi I state of stress, whereas the above calculation is uniaxial. Also, the analysis is elastic. Nevertheless, the 36 MPa figure is considerably in excess of the $1.3 \mathrm{kPa}$ from VSH 2 . In fact, it is considerably larger than the in sitv vertical stress of 7.9 MPa reported at SFT-C. 7,12 Hence, the pillars would end up in a state of large net tension--a unique occurrence, indeed. Besides, our limited pillar stress measurenents have indicated compession to exist.

In sumary, it appears that the unique horizontal shrinkage of the pillars, reported earlier, ${ }^{2,6}$ is neither consistent with model studies, nor explained from stress-strain relations for the rock mass. On the other hand, there is no difficulty in providing reasonable explanations for the reported localized decreases in vertical pillar stress.

The next sections describe the new modeling of the nine-by, performed with the JPIAXP code. The new analysis is explained first, and then details are given on the results of both the unjointed and the jointed analyses. 


\section{NEN MODELS OP THE MINE-BY}

\subsection{THE JPLAXD CODE}

JPLAXD is a plane and axisymetric finite element progran developed by the first author. ${ }^{8}$ The code is specifically directed at the analysis of structures in rock. To that end, it contajns a library of solid and joint elements. ${ }^{13}$ Both the solids and the joints can exhibit strain softening and dilatancy in the post-peak region. ${ }^{14-16}$ The progran also includes such features as mesh generation, restart capability for sequential excavation or construction, and plotting routines for stresses and displacements.

\subsection{THE JPLAXD ANALYSES}

To refine the analysis of the SFT-C mine-by we provided the following features which were not included in the previous models:

- Representation of öiscrete geological discontinuities, such as major joints and shears observed around the tunnels.

- Strain-softening and dilatancy of rock elements in the post-peak region.

- A field-measured input of rock mass modulus. ${ }^{12}$

- A field-measured input of in situ stresses. 7,12

- A Poisson's ratio derived from field stress measurements. 12

- A parametric variation of the ratio of horizontal to vertical stresses, between 0.5 and 3.5 .

At the outset, we realized that, in spite of their sophistication, the improved models still are two-dimensional approximations. They assure that the strike of the discrete shears and master joints is parallel to the longitudinal direction of the tunnels, whereas their true strike at climax was 10 to 30 degrees away. To do justice to the geology around most underground caverns, one should use three-dimensional models with both discrete and ubiquitous jointing. The few three-dimensional jointed finite elament models in existence, which were reviewed in Ref. 13, are quite elementary; dilatancy and strain-softening are not accounted for in the solid materials, or in the discentinulties. There does not exist a three-dimensional ubiquitous-joint model in any generally available three-dimensional numer loal model. It would seem that much development is needed to remedy these shortcomings. 
Two types of models were adopted: unjointed (Fig. 7) and jointed (Figs. 8 and 9). The jointed models were constructed after consultation with the SFT-C field geologist, ${ }^{17}$ to illustrate typical geometries of shears and master joints at stations $2+83$ and $3+45$. The unjointed models were used primarily to study the effect of the stress ratio on pillar response during mine-by. Three analyses were performed with the jointed models:

- Station $2+83$ with non-dilatant joints.

- Station $2+83$ with dilatant joints.

- Station $3+45$ with non-dilatant joints.

In all cases the stress ratio was $\sigma_{h} / \sigma_{v}=1.2$, to conform with field measurements. 7,12

With all the models, jointed or not, the calculations were performed in a sequence of four so-called runs:

- Run 1: obtain an equilibrium of the full mesh, without excavation.

- Run 2: excavate the two side drifts.

- Run 3: excavate the heading of the center drift.

- Run 4: excavate the bench of the center drift.

Runs 2, 3, and 4 were restarted from the equilibrium obtained in the previnus run. In cases when rock or joint failure takes place, the equilibrium is attained through a few (2-5) iterations in the run. The program automatically updates solid and joint properties, to be compatible with the input of constitutive relations.

In the absence of joints, one can take advantage of the symmetry of the SFT-C caverns, so that the unjointed models show only half of the tunnels.

\subsection{IN STTU GEONECAANICS AT SFT-C}

Because of the need for realistic input in the new calculations, a comprehensive field-oriented program ${ }^{12}$ was completed prior to the analysis reported here.

The wor $k$ consisted of:

- A detailed inspection of the three drifts, to identify the major geological discontinuities which should be represented discretely in the new finite element models.

f. salculation of the Rock Quality Designation (RQD) for cores obtained in NX holes MBI-7 and MBI-14, which $r$ an horizontally through the pillars in the vicinity of stations $2+87$ and $3+49$ (FIg. 1 ). 


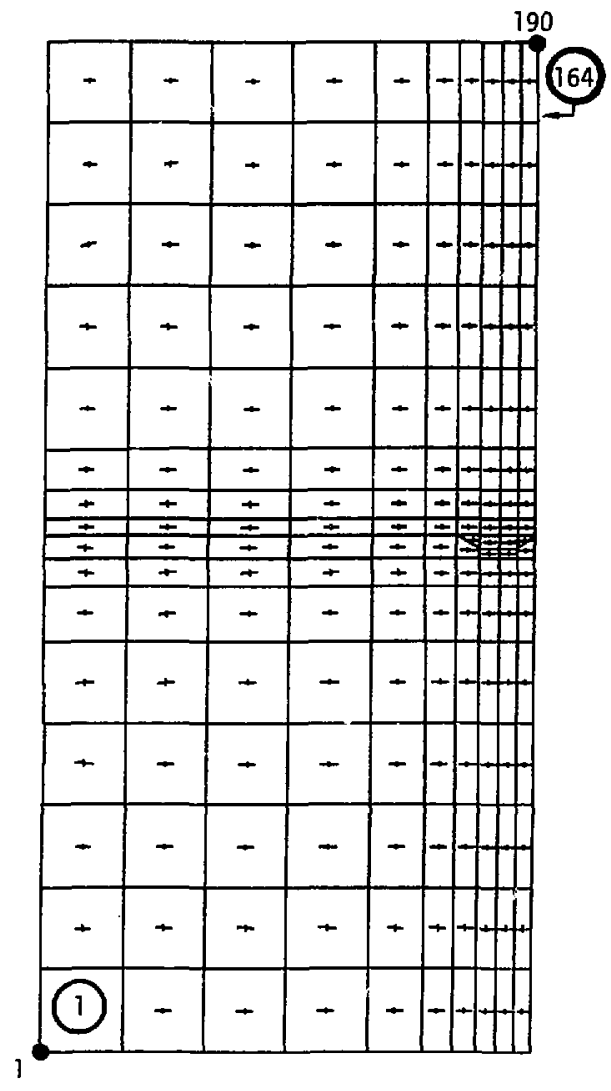

FIG. 7. Unjointed mesh of SFT-C caverns (190 nodes, 164 elements). 


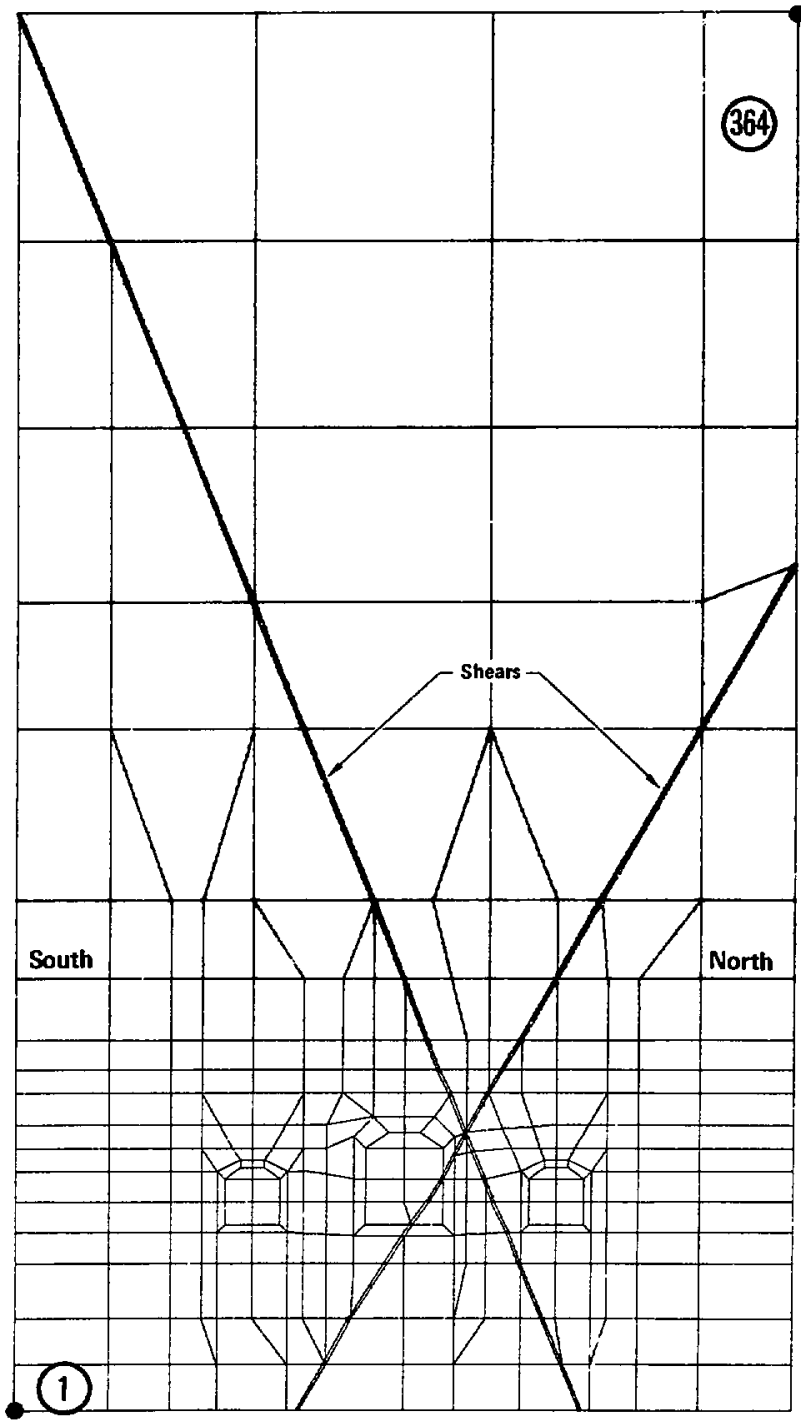

FIG. B. Jointed meah of the SFT-C caverns at station 3+45 (381 nodes, 380 elements) . 


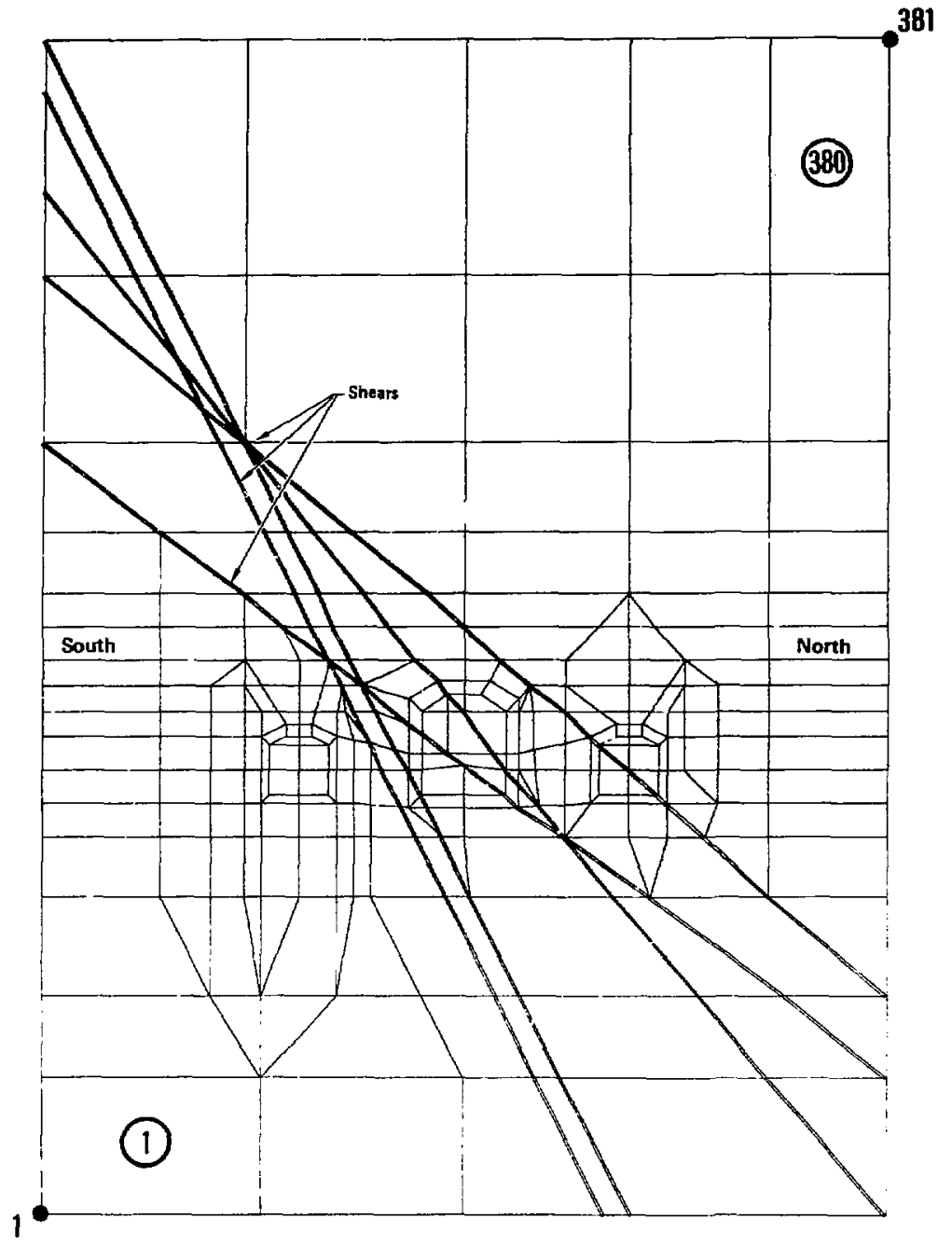

FIG. 9. Jointed mesh of the SFT-C caverns at station $2+83$ (375 nodes, 364 elements). 
- A series of rock mass deformability tests in MBI-7 and MBI-14 with the NX borehole jack, and with a modified NX jack also used for stress measurements.

- A series of "petite sismique" tests across the two pillars, in which the frequency of horizontally polarized shear waves was measured.

- Estimation of rock mass modulus based on calculation of Rock Mass Rating (RWR) and $Q$ rating for the climax granite.

- Reanalysis of previous stress measurements by the U.S. Geological Survey ${ }^{7}$ to obtain stresses parallel and perpendicular to the tunnels, from which an in situ poisson's ratio could be valculated.

- A series of stress measurements in both pillars by borehole jack fracturing in holes MBI-7 and MBI-14.

- A series of undercoring stress measurements at mid-length of each heater drift, to obtain values of tangential stresses.

\subsection{CLIMAX STOCR PROPERTIES TNPUT}

The input for deformation properties of rock and joints was derived from the field testing and from previous experience with testing of granite joints. The shear strength parameters for the joints also were selected from experience. However, because there is no experience with the in situ strength of granite rock masses, we adopted the minimum values of shear strength parameters which would keep the caverns stable. So, the new analyses can be used to estimate a lower bound for the in situ strength of the climax stock. This strength estimate can be compared to estimates for other granites. 18

The initlal material properties are summarized in Tables 3 and 4 . When further damage takes place in any rock element or joint element, the material properties are automatically readjusted internally in accordance with the constitutive laws. 


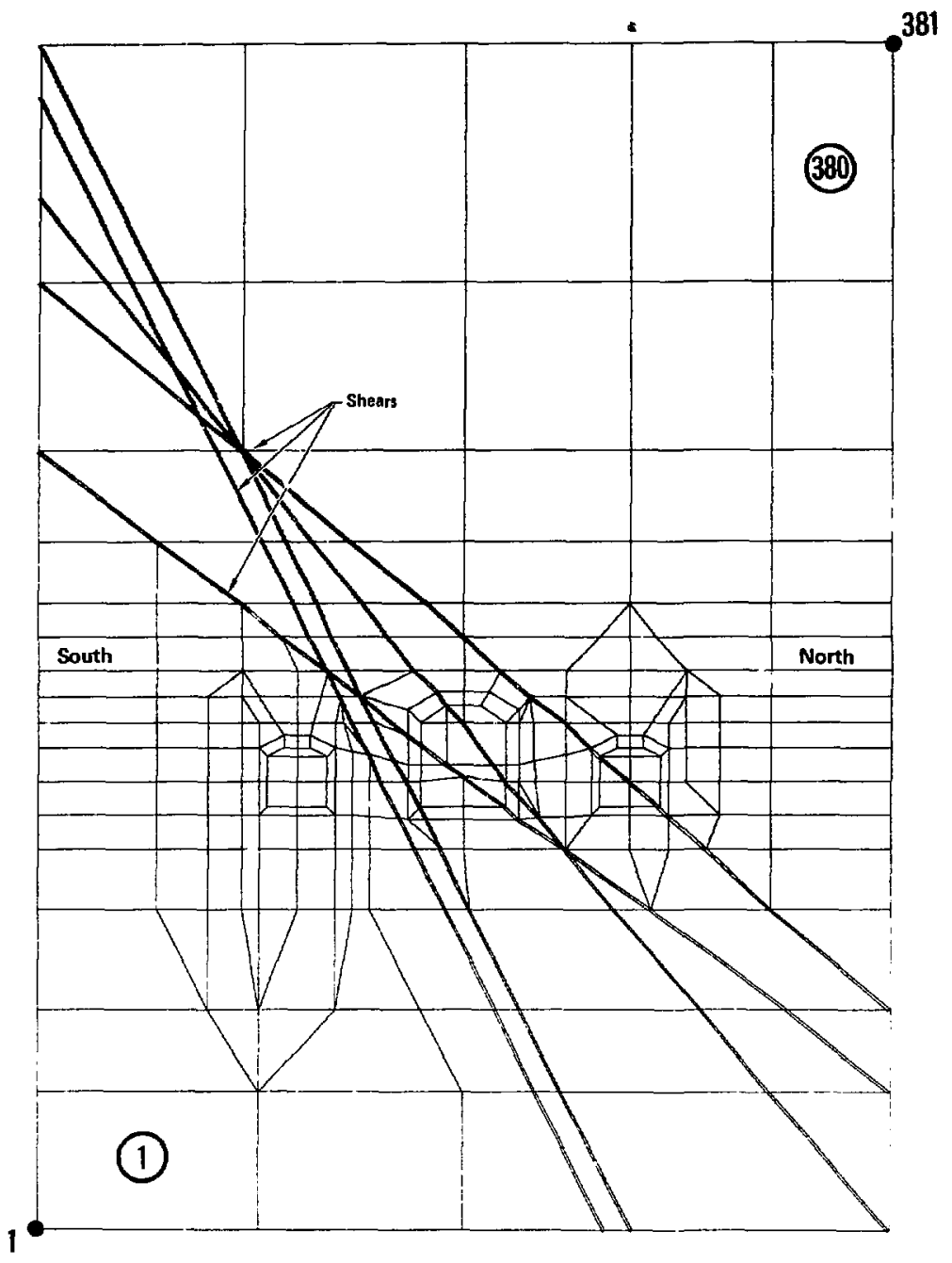

FIG. 9. Jointed mesh of the SFT-C caverns at station 2+83 (375 nodes, 364 elements). 
- A series of rock mass deformability tests in MBI-7 and MBI-14 with the NX borehole jack, and with a modified NX jack also used for stress measurements.

- A series of "petite sismique" test.s across the two pillars, in which the frequency of horizontally polarized shear waves was measurea.

- Estimation of rock mass modulus based on caiculation of Rock Mass Rating (RMR) and $Q$ rating for the Climax granite.

- Reanalysis of previous stress measurements by the U.S. Geological Survey ${ }^{7}$ to obtain stresses parallel and perpendicular to the tunnels, from which an in situ Poisson's ratio could be calculated.

- A series of stress measurements in both pillars by borehole jack fracturing in holes MBI-7 and MBI-14.

- A series of undercoring stress measurements at mid-length of each heater orift, to obtain values of tangential stresses.

\subsection{CLIMAX STOCK PROPERTIES INPUT}

The input for deformation properties of rock and joints was derived from the field testing and from previous experience with testing of granite joints. The shear strength parameters for the joints also were selected from experiarce. However, because there is no experience with the in situ strength of granite rock masses, we adopted the minimum values of shear strength parameters which would keep the caverns stable. So, the new analyses can be used to estimate a lower bound for the in situ strength of the Climax stock. This strength estimate can be compared to estimates for other granites. 18

The initial material properties are summarized in Tables 3 and 4 . When further damage takes place in any rock element or joint element, the material properties are automatically readjusted internally in accordance with the constitutive laws. 
TABLE 3. Initial values of rock properties used for JPIAXD calculations.

\begin{tabular}{lccc}
\hline \multicolumn{1}{c}{ Property } & $\begin{array}{c}\text { Intact } \\
\text { rock }\end{array}$ & $\begin{array}{c}\text { Damaged } \\
\text { rock }\end{array}$ & $\begin{array}{c}\text { Excavated }^{\mathbf{b}} \\
\text { rock }\end{array}$ \\
\hline Mass density & 2.65 & 2.65 & $1^{-2}$ \\
Modulus (GPa) & 30 & 10 & $10^{-2}$ \\
Poisson's ratio & 0.25 & 0.35 & 0.25 \\
Peak cohesion (MPa) & 7 & 3.5 & $10^{10}$ \\
Residual cohesion (MPa) & 0 & 0 & $10^{10}$ \\
Peak friction ( ${ }^{\circ}$ ) & 60 & 45 & 0 \\
Residual friction ( $\left.{ }^{\circ}\right)$ & 45 & 45 & 0 \\
Tensile strength $(\mathrm{MPa})$ & 10 & 2.7 & $10^{10}$ \\
\hline
\end{tabular}

a Damaged rock surrounds the drifts to a depth of 0.5 to $1 \mathrm{~m}$ (Figs. 8 and 9).

b The excavated rock is made very light and soft, but strong enough to bypass the failure criterion routines.

TABLE 4. Initial values of joint properties used for JPIAXD calculations.

\begin{tabular}{lccc}
\hline \multicolumn{1}{c}{ Property } & $\begin{array}{c}\text { Joint in } \\
\text { intact rock }\end{array}$ & $\begin{array}{c}\text { Joint in } \\
\text { damaged rock }\end{array}$ & $\begin{array}{c}\text { Excavated } \\
\text { joint }\end{array}$ \\
\hline Normal stiffness (MPa/m) & $10^{5}$ & $10^{5}$ & $10^{-3}$ \\
Shear stiffness (MPa/m) & 2700 & 2700 & $10^{-4}$ \\
Maximum closure (m) & $2.10^{-3}$ & $2.10^{-3}$ & 200 \\
Peak cohesion intercept (MPa) & 5 & 5 & 0 \\
Peak cohesion & 0 & 0 & 0 \\
Initial jilation angle $\left({ }^{\circ}\right) \mathrm{C}$ & 10 & 10 & 0 \\
Critical normal stress (MPa) & 30 & 30 & $10^{10}$ \\
Tensile strength (MPa) & 0 & 0 & 10 \\
Residual Eriction $\left({ }^{\circ}\right)$ & 40 & 25 & 0 \\
\hline
\end{tabular}

${ }^{a} c_{p}$ in Fig. 10 .

b zero, because both envelopes go through the origin.

c $\delta_{0}$ in Fig. 10; zero for non-dilatant joints. The instantaneous dilation angle, $\delta$, varies continuously with the normal joint stress, $\sigma$.

d $\sigma_{c}$ in Fig. 10; zero for non-dilatant joints.

e Peak friction is $\phi_{p}$ in Fig. 10; residual friction is $\phi_{r}$. 


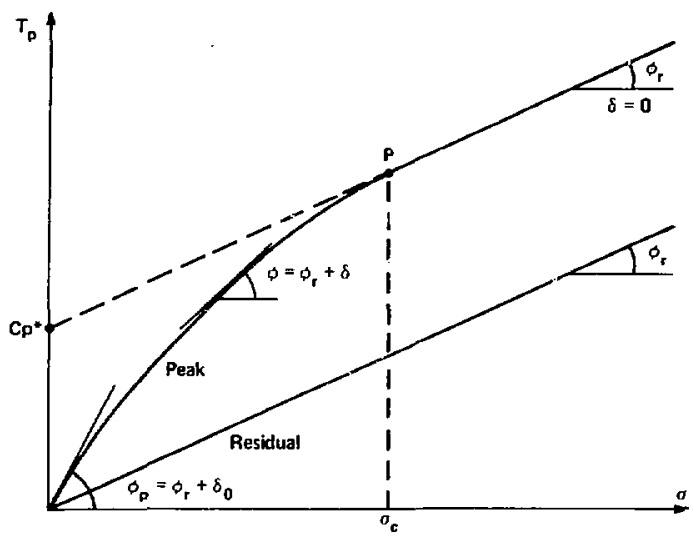

FIG. 10. Peak and residual shear strength envelopes for rock joints.

\section{RESULTS FROM THE UNJOINTED MODELS}

Four unjointed cases were studied. The ratio of horizontal to vertical in situ stresses, prior to mining, was given values of $\sigma_{h} / \sigma_{v}=0.5$, 1.2, 2.14, and 3.5. The detailed graphs and plots from these models are presented in Appendix A. Figures A-1 to A-4 show two sets of results:

- The pillar displacements during mine-by (runs 3 and 4).

- The pillar and abutment stresses in all four runs. In summary, the models show that during the mine-by:

- The center (canister) drift always closes horizontally.

- All caverns close vertically.

- Both pillars shift toward the center of the canister drift.

- Both pillars always increase in width; this increase is more pronounced with a higher $\sigma_{h} / \sigma_{v}$ ratio:

\begin{tabular}{lllll}
$\sigma_{\mathrm{h}} / \sigma_{\mathrm{v}}$ ratio & 3.50 & 2.14 & 1.20 & 0.5 \\
\hline $\begin{array}{l}\text { increase in } \\
\text { pillar width }(\mathrm{mm})\end{array}$ & 4.96 & 3.08 & 1.78 & 0.83
\end{tabular}

- The mean vertical pillar stress always increases.

- With the same material properties for the intact rock as in the jointed model.s, there was no rock failure. The lowest shear factor of safety 
in any element (F.S.) was always $>1.0$. The case $\sigma_{h} / \sigma_{v}=1.2$ was the most favorabie:

$\begin{array}{lllll}\sigma_{\mathrm{h}} / \sigma_{\mathrm{v}} \text { ratio } & 3.50 & 2.14 & 1.20 & 0.5 \\ \begin{array}{l}\text { lowest F.S. for } \\ \text { any element }\end{array} & 1.83 & 3.89 & 4.74 & 4.19\end{array}$

However, calculations from more realistic models, with discrete shears and jointr, indicate sone siight rock damage, as discussed next. The finer meshes used i', the jointed models also provide a better analysis in regions of stress concentrations.

\section{RESULTS PROH THE JOINTED HODELS}

For each of the three models, the following information is presented in Appendices $\mathrm{B}$ to $\mathrm{D}$ :

- Convergence of the 3 drifts during complete excavation (runs 2, 3, and 4).

- Convergence of the 3 drixts during mine-by only (runs 3 and 4).

- Horizontal convergence for the drifts and pillars; the field values from tipns and MPEs are compared to the JPLAXD results.

- Movements of the three sets of MPEs during the mine-by (runs 3 and 4 ). The JPLAXD calculations of anchor movements are compaxed to the calcul tions with ADINA and to the field data.

- Vertical stresses in both pillars ( $r$ uns 1 through 4).

- Principal stressez around the caverns for each mining step.

- Rock and joint failures during the mining of the three caverns (runs 2, 3, and 4).

\subsection{STATION 2+83, NON-DILATANT JOINTS}

The information contained in Figs. B-I to B-7 can be summarized as follows:

- During the complete mining, all three caverns close, both horizontally and verticaily, and both pillars expand laterally (Fig. B-1). 
- During the mine-by portion of the mining, all caverns close vertically, the center drift closes horizontally and the walls of the two heater drifts move towards the center drift, with a slight net opening of those drifts. Both pillaz rpand laterally (Figs. B-2 and B-3).

- In Fig. B-3, the $h_{k} \cdot:$ atal convergence values obtained with JPLAXD are explained by the follow. , vatern of movements for points A through $\mathrm{P}$ :

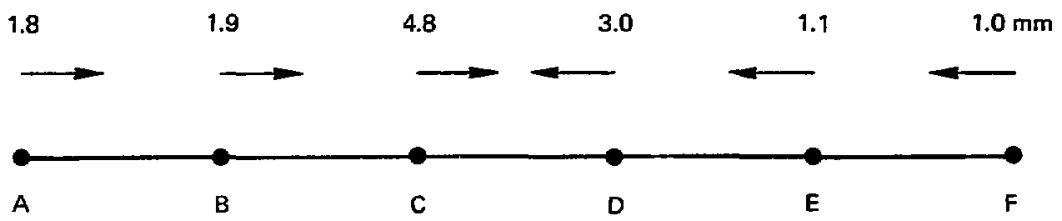

The directions of movements from ADINA were identical to these. However, once again it is not possible to establish such a coherent pattern of wovenents for the data reported from the field, ${ }^{2,6}$ unless $r$ e assumes that the center drift expanded laterally upon mining. This would be contrary to all mechantcal models considered so far, with a wide range of stress ratios. It is also contrary to mining experience.

- The MPE anchor movements obtained with JPIAXD are gencrally higher than those obtained with the ADINA scoping calculations; this could have been expected because of the jointing and lower modulus values used in the JPLAXD models. None of the calculated movements is well matched by data reported from the field (Fig. B-4). For the inclined extensometers, the percentage of anchor movements in which the field values and the cocie calculations differ by a factor of two or more is 50 with ADINA and 87 with JPIAXD. For the horizontal extenscmeters the discrepancy is 1008 , since all reported movements are in the opposite direction from those calculated with Dorh JPLAXD and ADINA.

- The vertical pillar stress changes during mine-by, obtained with JPIAXD (Fig. B-5), are consistent with the field observations from vSM stress gages at station $2+80$ (Table 2), unlike pillar stresses calculated from previous models. ${ }^{2,6}$ The agreement is particularly good for stress relief in the skin of the pillars. The 10.1 kPa decrease obtained in the North pillar is quite close to the $9.7 \mathrm{MPa}$ reported from VSH-1. The calculated velue was $9.2 \mathrm{MPa}$ in the south pillar, which did not have stress gages. The model also shows a 1.2 MPa localized decrease in the core of the south pillar, due to the particular jointing. This is close to the $1.3 \mathrm{MPa}$ reported in the core of the North pillar. Whereas our jointing model of the North pillar may not be 
complete, it does show that a localized stress decrease can be explained by joint patterns.

- Notwithstanding localized decreases, the wodels show that the average vertical pillar stress increases during the mine-by. The calculated increments are 2.05 and $1.75 \mathrm{kPa}$ for the North and South pillars, respectively.

- The vertical stress is also shown to increase in the abutaents, beyond the walls of the heater drifts (Fig. B-6). A confirmation of these calculations is not possible, because there were no stres-gages in the abutments.

- For the shear strength parameters selected, only ninor damage is calculated around the caverns during complete mining (Fig. B-7). This result is consistent with the field observations.

\subsection{STATION $2+83$, DILATANT JOINTS}

The detailed information from this model is contained in Figs. C-1 to C-7. In summary:

- The same statements as in the non-dilatant case apply to the deformation patterns.

- Again, the pillar stresses calculated are in good agreement with the field reports. The destressing in the pillar skin is 10.1 and 9.3 MPa for the North and South pillars respectively. The decrease in the core of the South pillar is calculated as $0.7 \mathrm{Mpa}$.

- Rock damage is calculated to be the sane as in the no dilation case, but joint shear failure has disappeared.

\subsection{STATION 3+45, NON-DILATANT JOINTS}

Figures D-1 to D-7 contain the detailed resilts from the model. In sumary:

- The pattern of horizontal deformations is similar to that at station $2+83$, except for the slight closure of the heater drifts during mine-by.

- The same conclusions as before apply to MPE calculations and field values. For the inclined extensometers, the percentage of discrepancy by a factor of two or more between measured and calculated movements is 638 with ADINs and 97\% with JPLAXD. Again, the discrepancy is 1008 with both code calculations for the hor izontal extensometers. 
- Again, both pillars expand laterally during mine-by .

- The JPIAXD-calculated decrease in vertical pillar stress in the skin of the North pillar was $6.9 \mathrm{MPa}$. This is quite close to the 7.0 MPa reported from VSH 3 , at station $3+02$. The calculated value was $8.5 \mathrm{MPa}$ for the South pillar, which did not have 2 tress gages. As opposed to station $2+83$, an increase is calculated for the vertical stress at mid-pillar, during mine-by. since there was no stress gage at station $3+45$, one cannot verify this result.

- Again, rock damage is calculated to be slight, which is compatible with field observations.

\section{SUMYRI - RECOLIENDATIONS}

\subsection{SUMPART AND CONCLUSIONS}

An analysis of the mine-by at SFT-C was performed by means of refined finite element models using the JPLAXD code. 8 The input data were derived from our field program, which is reported separately. ${ }^{12}$ In sumary:

- Unlike the results obtained with previous models, ${ }^{2,6}$ the vertical pillar stresses obtained with the JPLAXD code agree with the field observations from VSM stress gages. This agreenent holds for calculations for the stress relief due to blasting, in the skin of the pillars, and for localized vertical stress decrease due to joint patterns, in the core of the pillars.

- Notwithstanding the above local decreases, all calculations show that the mean vertical stress increases in both pillars, during the mine-by.

- Overall, the dilation effects were small because of the geometry of the joints, which were not strongly restrained against opening during shear. with different joint patterns, such dilation effects can be very pronounced. 16

- A set of rock mass shear strength paraweters was selected by successive trials to indicate only ainor damage around the caverns and in the pillars, during mining. This procedure is consistent with the field chservations. It is also consistent with expected increases in average vertical pillar stress during mining, when pillars do not fail.

- Hence, the shear strength values from the JPLAXD models can be used as a lower-bound estimate of the in situ strength of the Climax granite. These values can be compared to strength estimates for other granites. 18 
- The multi-position extensometer (MPE) movements obtained with the JPLAXD analysis are generally higher than those calculated with former models. ${ }^{2,6}$ This result was to be expected, because previous model s used modulus values derived from laboratcry tests.

- All modelis show that during mining of the center drift all caverns close vertically, and the center drift closes horizontally. The walls of the two heater drifts move toward the center drift, with a slight opening or a slight closing of the heater drifts, depending upon the geology.

- All calculations show both pillars expanding laterally during mine-by.

- The lateral contraction of the pillars, ieported from horizontal sPEs. leads to the very suspicious conclusion that the pillars end up in a state of tension.

- The values reported froa horizontal tapes appear to be unreliable. The reported pillar stress changes have been explained, but no explanation was found for the deformation reported from the wajority of tapes and MPEs. Neither the JPLAXD- nor the ADINA-calculated displacements are well matched by values reported from the field. The discrepancy by a factor of two or more is 568 with ADINA and 878 with JPLAXD for the 48 anchors from Inclined MPEs, and 1008 with both codes for the 12 anchors from horizontal wPEs. The total discrepancy rate for 60 anchors is 658 with ADINA and 898 with JPLAXD. With such discrepancies, does the problem lie with the models, with the field readings, or with both? The diagram below should help to answer the question. The "yes" or "no" refer to whether or not the various resules are consistent with each other, inside the models, in the field, or between field

Finite element models (JPLAXD and ADINA)
Field data from

tapes and MPEs

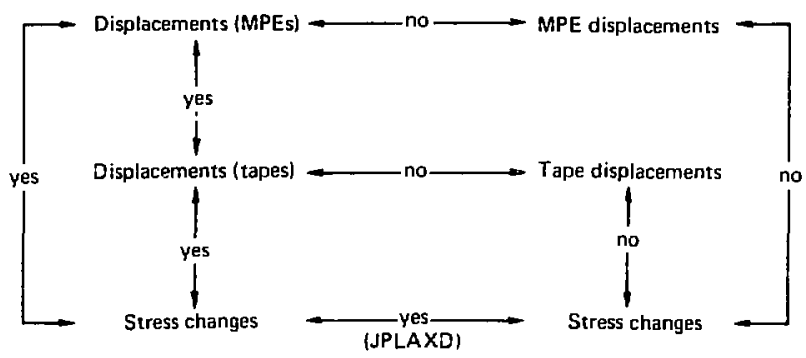


and models. Both finite element models, which have been tested extensively, are internally consistent, because displacements are used to calculate stresses.

The most logical conclusions to reach from this discussion are that:

- The pillar stress changes were correctly recorded and correctly modeled.

- The displacements calculated in the pillars are correct, because they are the values used to calculate pillars stresses.

- The pillar displacements reported from horizontal kPEs are not conslstent with the reported pillar stress changes.

- Data from the inclined 2PEs, which have a high discrepancy rate with the models, are not unrealistic. Local jointing can be responsible for these discrepancies. Hence, the models could be further improved if more geologic exploration were performed in the region above the caverns.

For now, it seems that the combination of the in situ geomechanics performed at SFT-C $\mathrm{C}^{12,17}$ and of the new analysis provides a coherent, although not quite complete, representation of the climax mine-by.

\subsection{RECOMRENDATIONS}

Considering the complexity of stress and deformation patterns in jointed media, ${ }^{19-22}$ we could further improve our understirding of the sFT-C mine-by by performing additional stress measurements in the two pillars and in the abutments of the heater drifts.

Notwithstanding the Improvement they represent, the new models remain two-dimensional approximations. As pointed out in a recent National Research Council report, ${ }^{23}$ the development of realistic three-dimensional models for jointed rock structures should be given nigh priority, in order to improve our geomechanical analyses. 
1. L. D. Ramspott, L. B. Ballou, R. C. Carlson, D. N. Montan, T. R. Butkovich, J. E. Duncan, พ. C. Patrick, D. G. Wilder, W. G. Brough, and M. C. Mayr, Technical Concept for a Test of Geologic Storage of Spent Reactor Fuel in the Climax Granite, Nevada Test Site, Lawrence Livermore National Laboratory, Livermore CA, DCRL-52796 (1979).

2. L. D. Ramspott, Climax Granite Test Results, Workshop on Thermamechanical Hodeling for a Hard Rock Waste Repository, Lawrence Livermore National Laboratory, Livermore, CA, UCAR-10043 (1979).

3. F. Maldonado, Sumnary of the Geology and Physical Properties of the Climax Stock, Nevada Test Site, Report from the 0.S. Geological Survey to the Nevada Operations Office, Department of Energy (1977).

4. R. J. Bathe, ADINA: A Finite Element Program for Automatic Dynamic Incremental Nonlinear Analysis, Massachusetts Institute of Technology, Cambridge, MA, MIT Report 82448-1 (1976).

5. P. K. Dutta, R. W. Hatfield, and P. H. Runstadler, Jr., Room and High-Temperature Calibration Characteristics of Irad Gage Vibrating Wire Stressneters, IRAD Gaye Co., Lebanon, NH, Report 80-2 to Lawrence Livermore National Laboratory, Livermore, CA, October, (1980).

6. T. Schrauf and M. Board, Instrument Selection, Installation, and Analysis of Data for the Spent Fuel Mine-by, Nevada Test Site, Climax stock, Lawrence Livermore National Laboratory, Livermore, CA, UCRL-15076 (1979).

7. W. I. Ellis, U. S. Geologic Survey Denver, Co, private communication to L. D. Ramspott, Lawrence Livermore National Laboratory, Livermore, CA (June 7, 1979) .

8. F. E. Heuze, JPLAXD: A Finite Element Program for Plane and Axisymmetric Analysis of Structures in Jointed Rccks, with Dilatancy and StrainSoftening - User's Manual, Lawrence Livermore National Laboratory, Livermore, CA, UCID-19047 (1981).

9. H. R. Pratt, R. Lingle, and T. Sehrauf, Laboratory Measured Material Properties of Quartz Monzonite, Climax Stock, Nevada Test Site, Lawrence Livermore National Laboratory, Livermore, CA, DCRL-15073 (1979).

10. F. E. Heuze, Scale Effects in the Determination of Rock Mass Strength and Deformability, Rock Mechanicis, v.12, 167 (1980). 
11. พ. R. Haversik, Detailed Analysis of Rock Fallure in Laboratory Compression Experiments, Ph.D. Thesis, University of Minnesota, Minneapolis, MN (1968).

12. F. F. Heuze, พ. C. Patrick, R. V. De la Cruz, and C. F. Voss, In Situ Geomechanics, Climax Granite, Nevada Test Site, Lawrence Livermore National Laboratory, Livermore, CA, UCRL-53076 (1981).

13. F. E. Heuze and T. G. Barbour, Nes Models for Rock Joints and Interfaces, Lawrence Livermore National Laboratory, Livermore, CA, UCRL-85222(1980).

14. F. E. Heuze, R. E. Goodman, and A. Bornstein, "Joint Perturbations and No-Tension Finite Element Solutions," Rock Mechanics, v.3. n.1, 13 (1971).

15. F. E. Beuze and T. G. Barbour, "Stability Analysis for Rock Structures," in Proc. 19th Symposium on Rock Mechanics, Stateline, Nevada, 1978, PP 452-460.

16. F. E. Heuze, "Dilatant Effects of Rock Joints," in Proc. 4th Congress Int. Soc. Rock Mechanics, Montreux, Switz., 1979, v.1. PP 169-175.

17. D. G. Wilder and พ. C. Patrick, Geotechnical stat'Is Report for Test Storage of Spent Reactor Fuel in Climax Granite, Nevada Test Site, Lawrence Livermore National Laboratory, Livermore, CA, UCRL-85096 (1980).

18. E. Hoek and E. T. Brown, "Empirical Strength Criterion for Rock Masses," ASCE. J. Geotech. Eng. Div., GT9, 1980, pp 1013-1035.

19. B. Amadei, University of California at Berkeley, Berkeley, CA, private communication $(1980)$.

20. B. A. Chappell, "Deformational Response in Discontinua," Int. J. Rock Mech. and Min. Sci., v.16, 377 (1979).

21. B. A. Chappel1, "Load Distribution and Redistribution in Discontinua," Int. J. Rock Mech, and Min. Sci., v.16. 391 (1979).

22. B. Singh, "Continuum Characterization of Jointed Rock Hasses. Part I : The Constitutive Equations. Part II: Significance of Low Shear Modulus," Int. J. Rock Mech. and Min. Sci., v.10, 311 (1979).

23. U.S. National Committee for Rock Mechanics, Rock Mechanics Research Requirements for Resource Recovery, Construction, and Earthquake Hazard Redilion, Report to the National Research Council, National Academy of Sciences, washington, DC (1981). 
Detailed Results from the Unjointed Hodels.

RUN 3

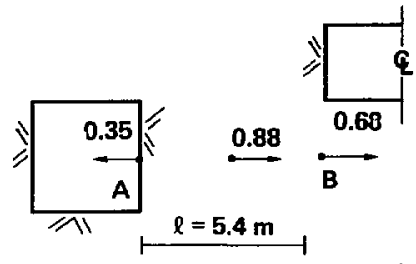

RUN 4

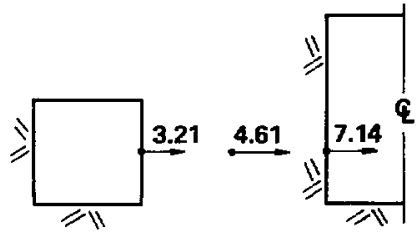

RUNS 3 + 4: $\Delta(A B)=4.96 \mathrm{~mm}$

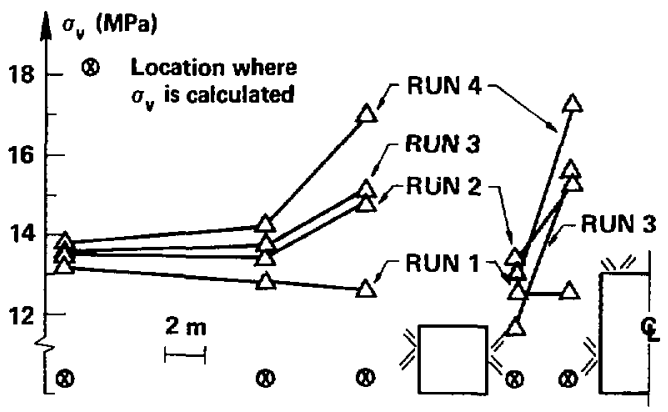

FIG. A-1. Horfzontal pillar deformations and vertical pillar stresses for the case $\sigma_{h} / \sigma_{v}=3.5$. 
RUN 3

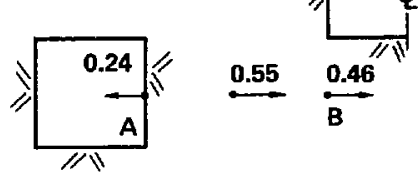

RUN 4

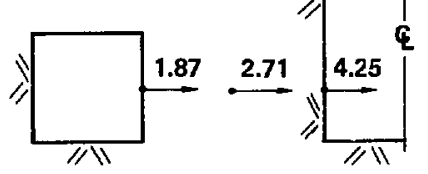

RUNS $3+4: \Delta(A B)=3.08 \mathrm{~mm}$

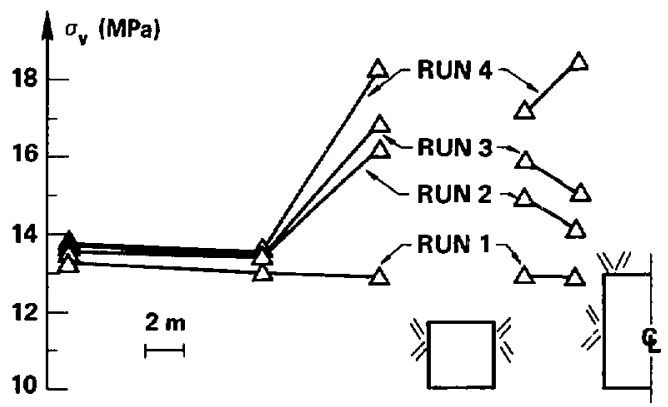

FIG. A-2. Horizontal pillar deformations and vertical pillar stresses for the case $\sigma_{h^{\prime}}{ }_{v}^{\sigma=2.14}$. 
RUN $3 \quad \sqrt{\frac{0.16}{A}} \stackrel{0.32}{\because} \frac{0.30}{B}$
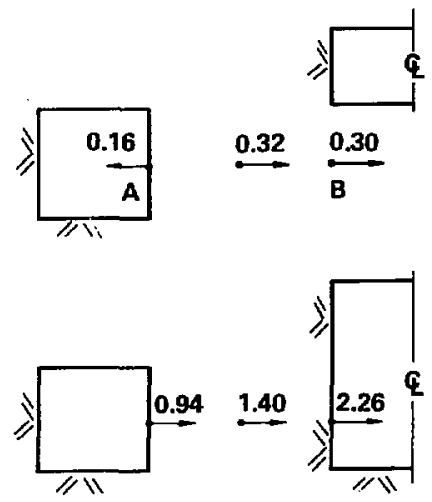

RUNS $3+4: \Delta(A B)=1.78 \mathrm{~mm}$

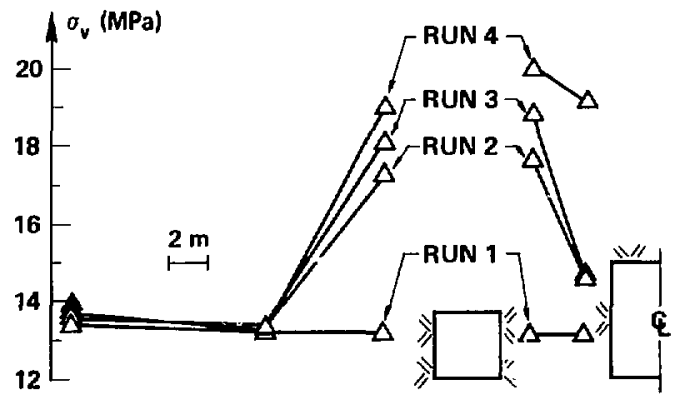

FIG. A-3. Horizontal pillar deformations and vertlcal pillar stresses for the case $\sigma_{h^{\prime}} v^{\sigma=1.2}$ 
RUN 3
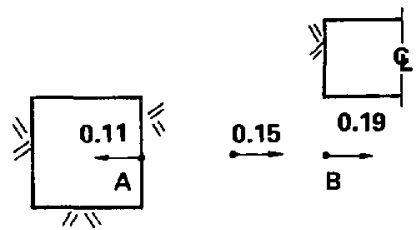

RUN 4
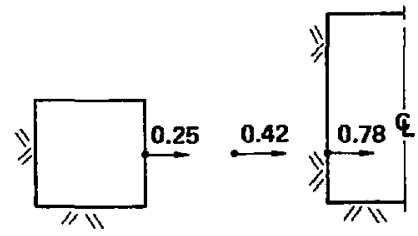

RUNS $3+4: \Delta(A B)=0.83 \mathrm{~mm}$

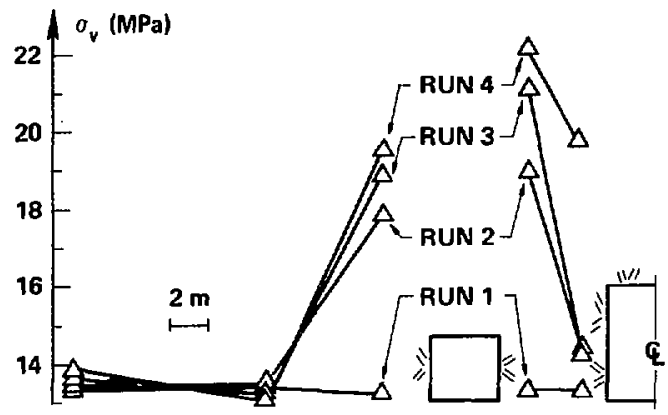

FIG. A-4. Horizontal pillar deformations and vertical piller stresses for the case $\sigma_{h^{\prime}} \sigma=0.5$. 
RUN 3
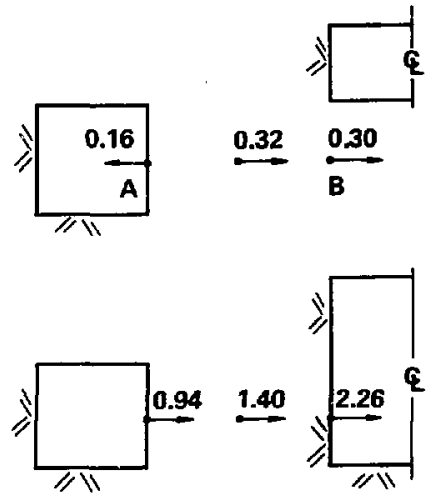

RUNS 3 + 4: $\triangle(A B)=1.78 \mathrm{~mm}$

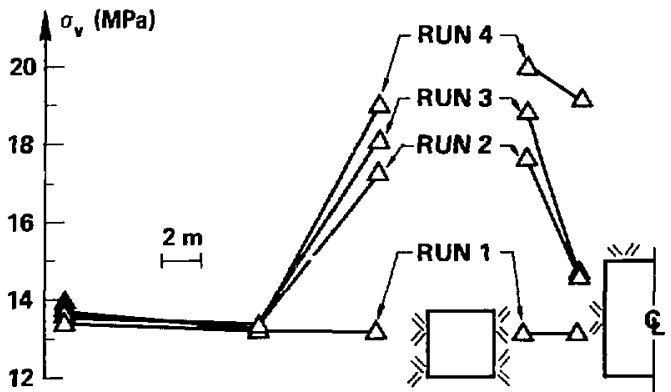

FIG. A-3. Horizontal pillar deformations and vertical pillar stresses for the case $\sigma_{h}{ }_{v}^{\sigma=1.2}$. 
RUN 3
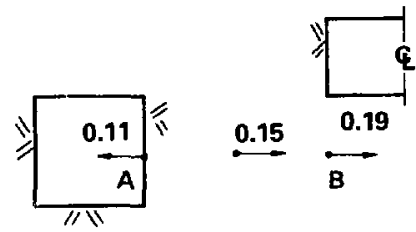

RUN 4

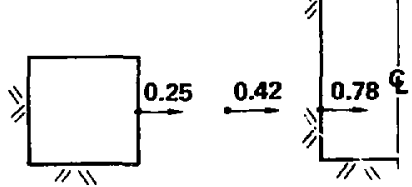

RUNS $3+4: \Delta(A B)=0.83 \mathrm{~mm}$

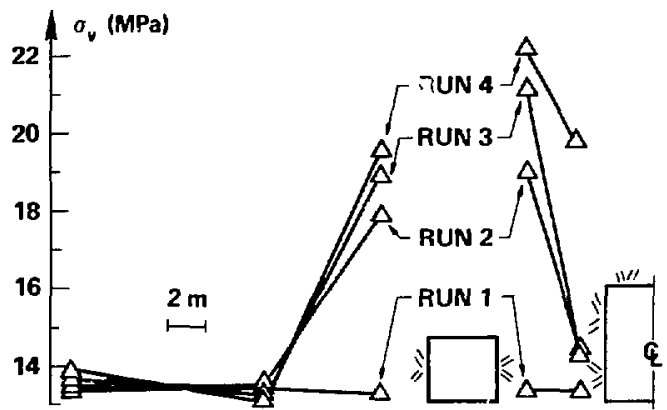

FIG. A-4. Horizontal pillar deformations and vertical pillar stresses for the case $\sigma_{h} /{ }_{p} \sigma=0.5$. 
APPENDIX B.

Detailed Results from the Jointed Models:

Station 2+83, Non-Dilatant Joints

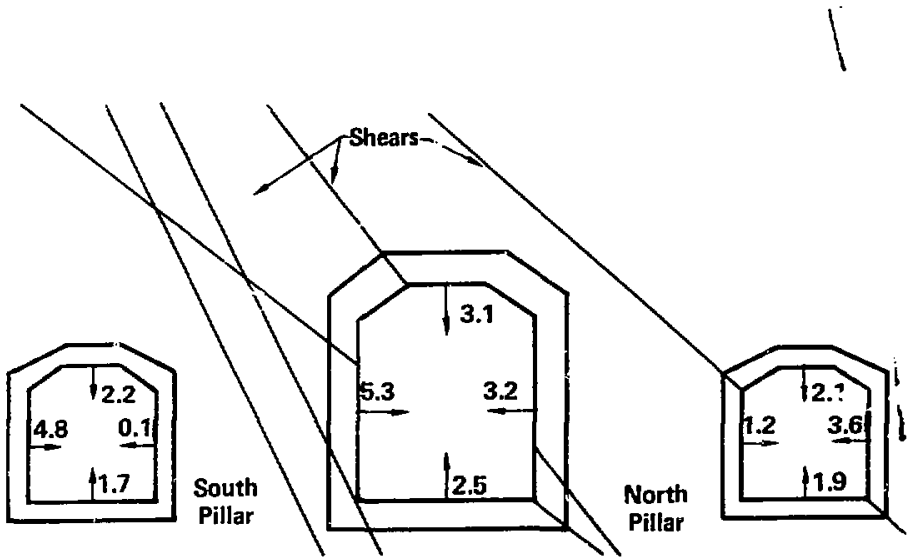

FIG. B-1. JPIAXD-calculated cavern closures (min) for the complete mining sequence. Station $2+83$, non-dilatant joints.

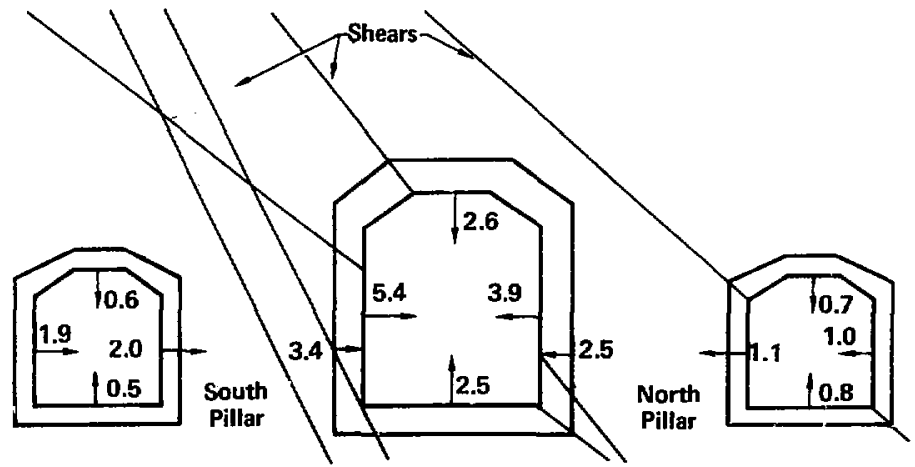

FIG. B-2. JPLAXD-calculated cavern closuros (mu) for the mine-by of the center drift. Station $2+83$, non-dilatant joints. 

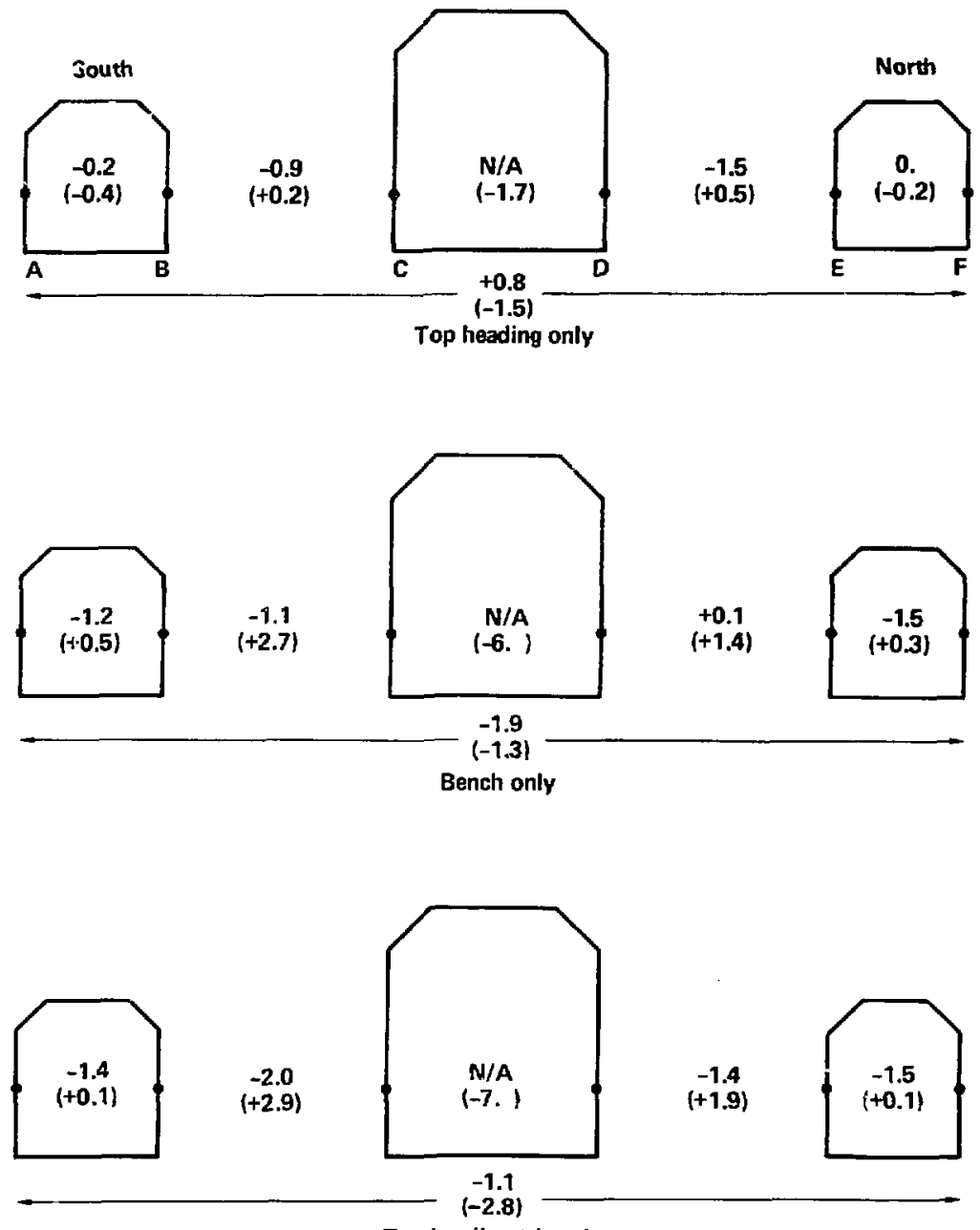

Top heading + bench

FIG. B-3. Comparison of field observations with (JPIAXD calculations) for the horizontal moverents across the three caverns, during mine-by (m) . Station $2+83$, non-dilatant joints. 

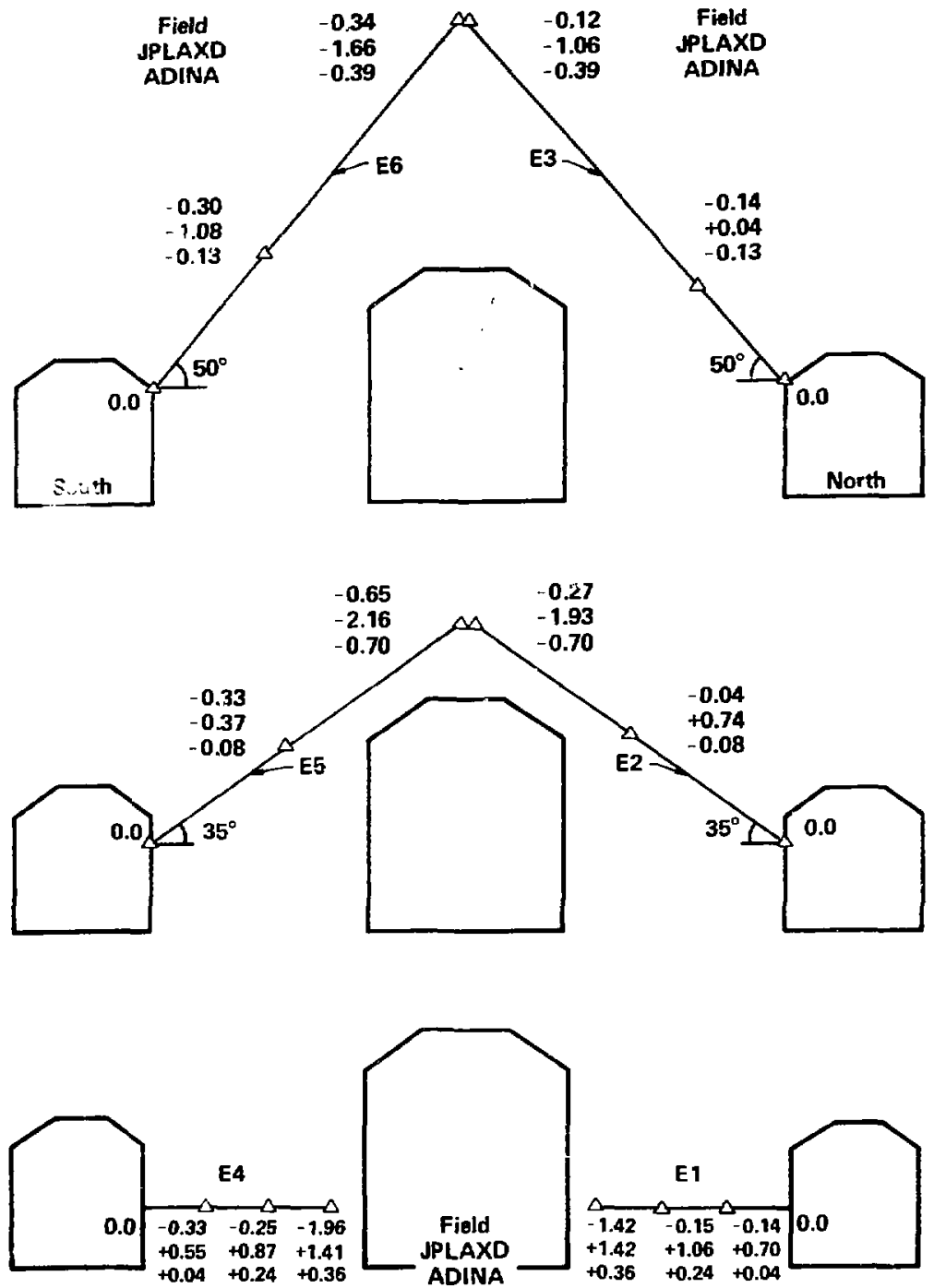

FIG. B-4. Comparison of field observations with JPLAXD and ADINA calculations, for the relative movements of MPE anchors during the mine-by (mm). Station $2+83$, non-dilatant joints. 

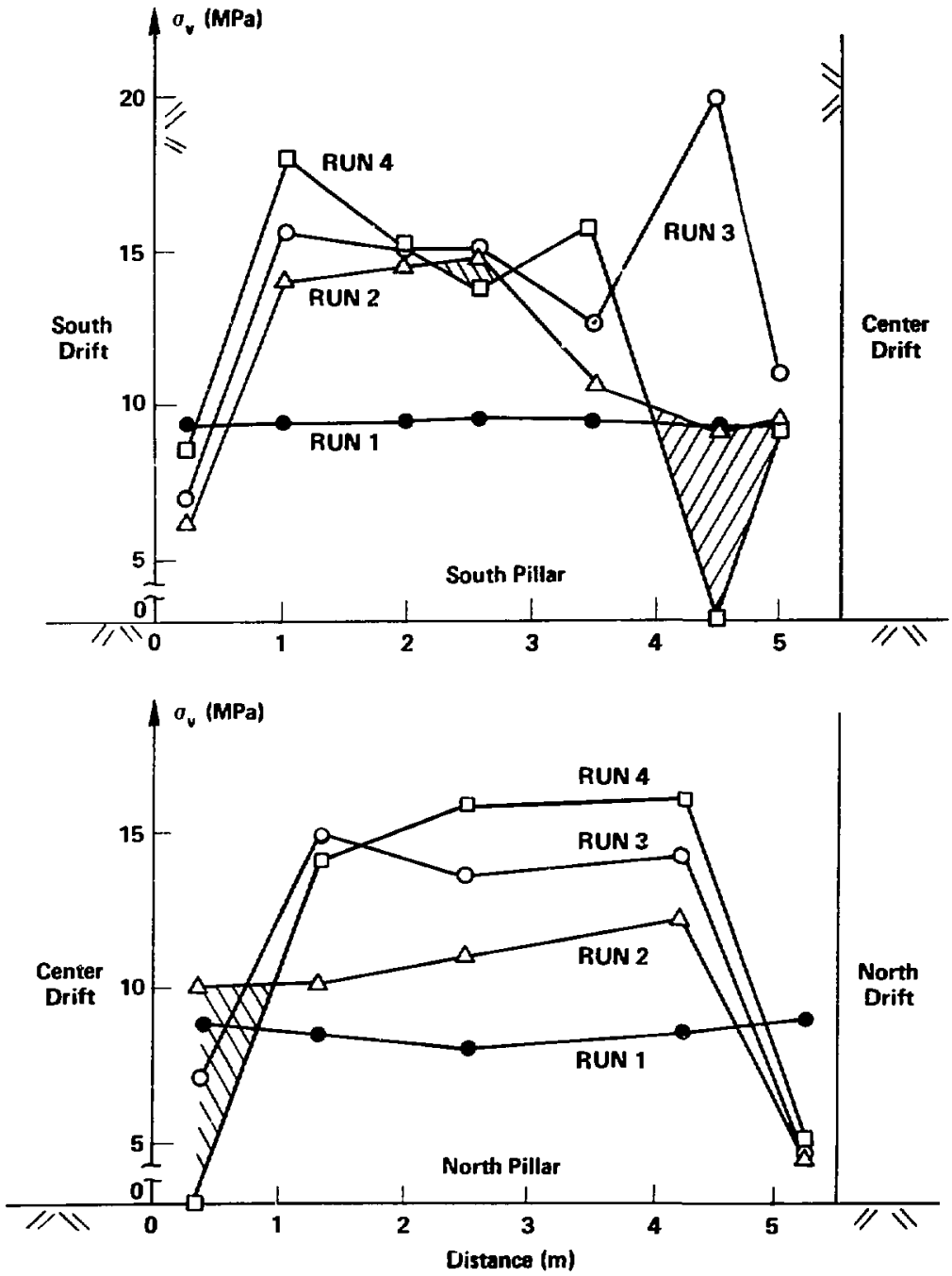

FIG. B-5. JPLAXD-calculated variation of vertical pillar stresses during the complete mining sequence. Hatching indicates a stress decrease during the mine-by. Station $2+83$, non-dilatant joints. 

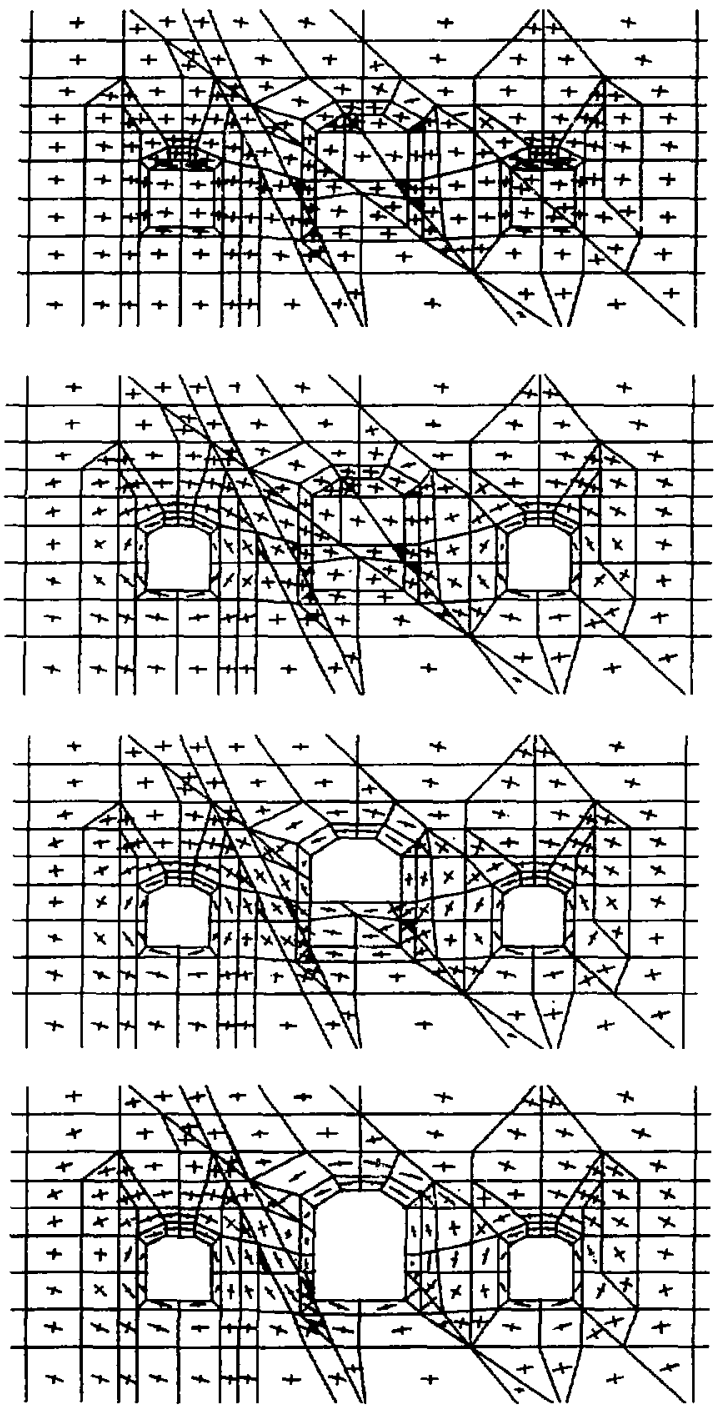

FIG. B-6. JPLAX principal stress plots for the complete mining sequence. Station 2+83, non-dilatant joints. 

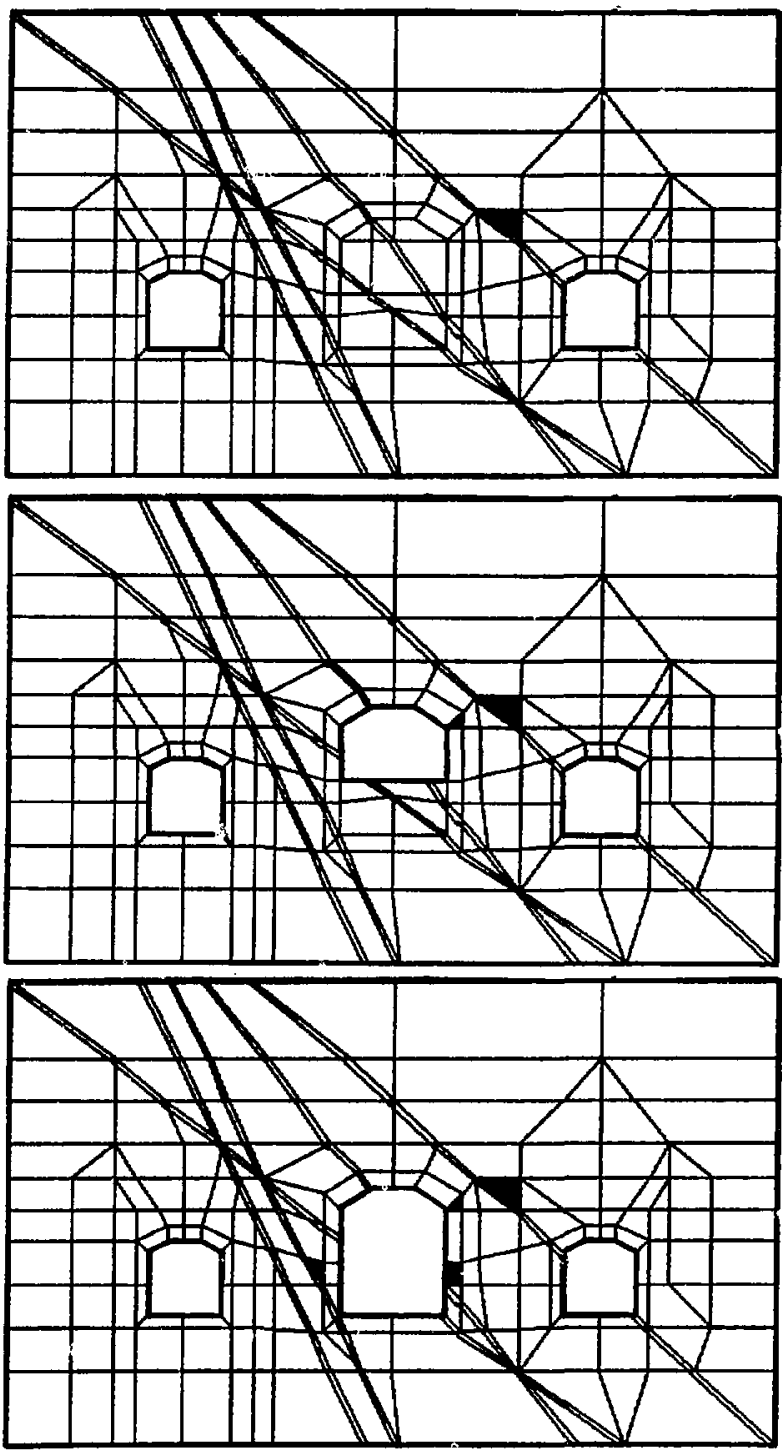

FIG. B-7. JPLAXD-calculated rock and joint failures in the mining sequence. Station $2+83$, non-dilatant joints. 
APPENDIX $C$.

Detailed Results from the Jointed Models:

Station 2+83, Dilatant Joints

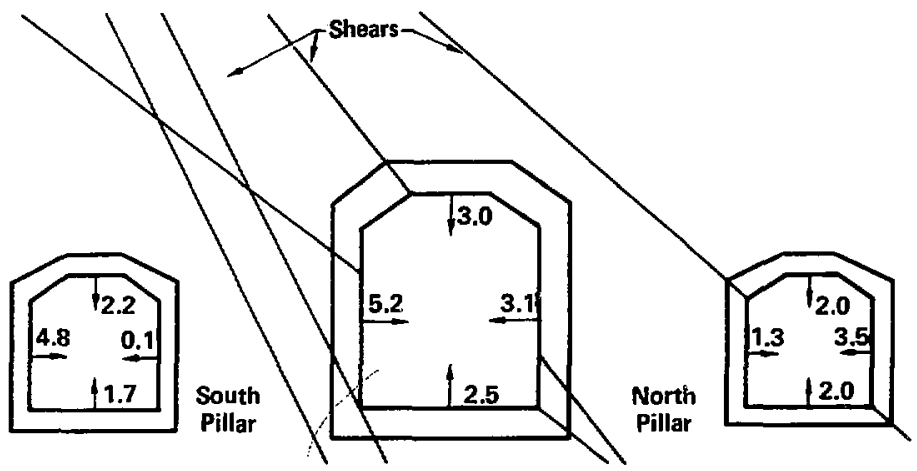

FIG. C-1. JPLAYD-calculated cavern closures (min) for the complete mining sequence. Station $2+83$, dilatant joints.

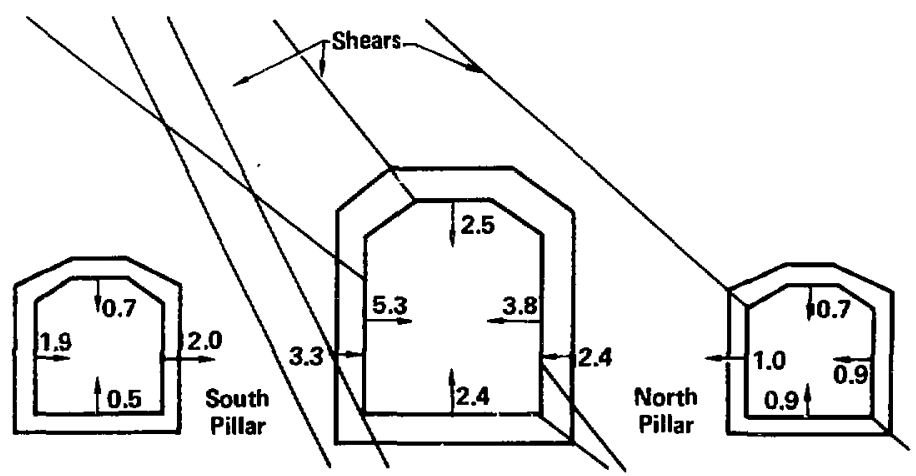

FIG. C-2. JPIAXD-calculated cavern closures (mm) for the mine-by of the center drift. Station 2+83, dilatant joints. 


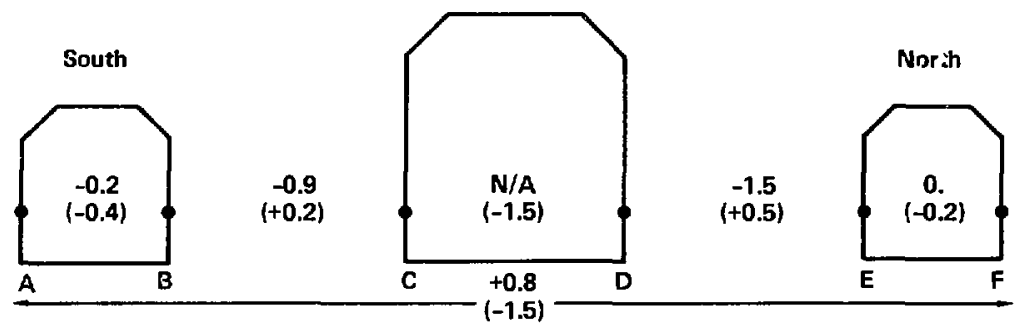

Top heading only
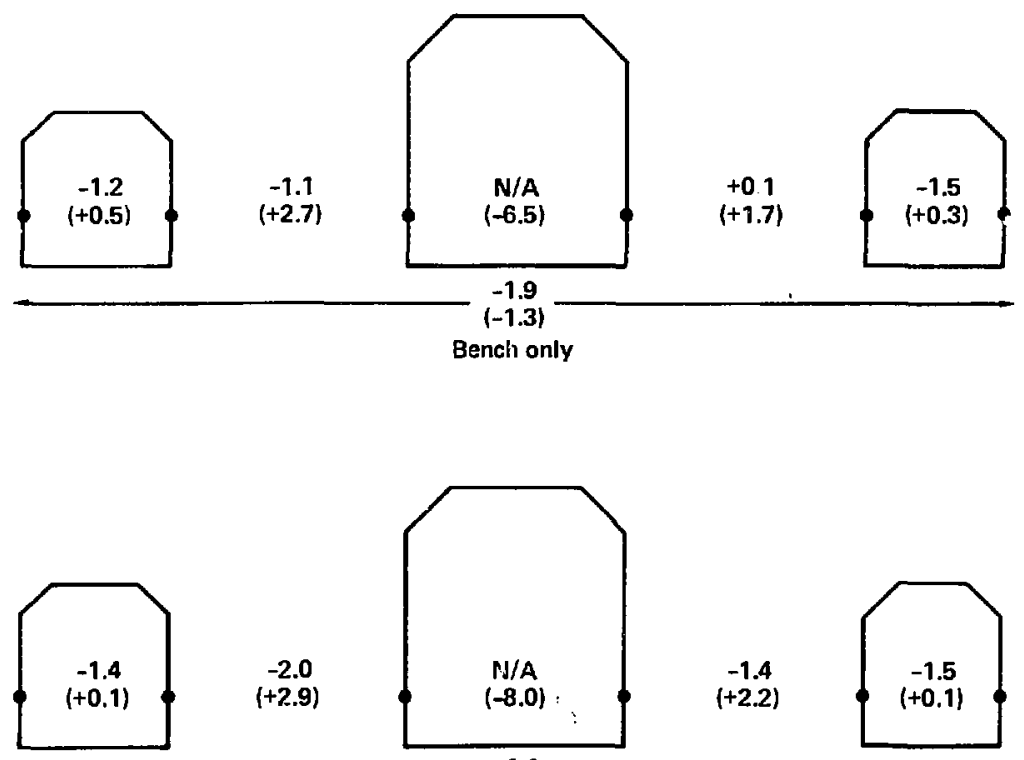

$-1.1$

(-2.8)

Top heading + bench

FIG. C-3. Comparison of field observations with (JPLAXD calculations) for the horizontal movements across the three caverns, during mine-by (min). Station $2+83$, dilatant joints. 

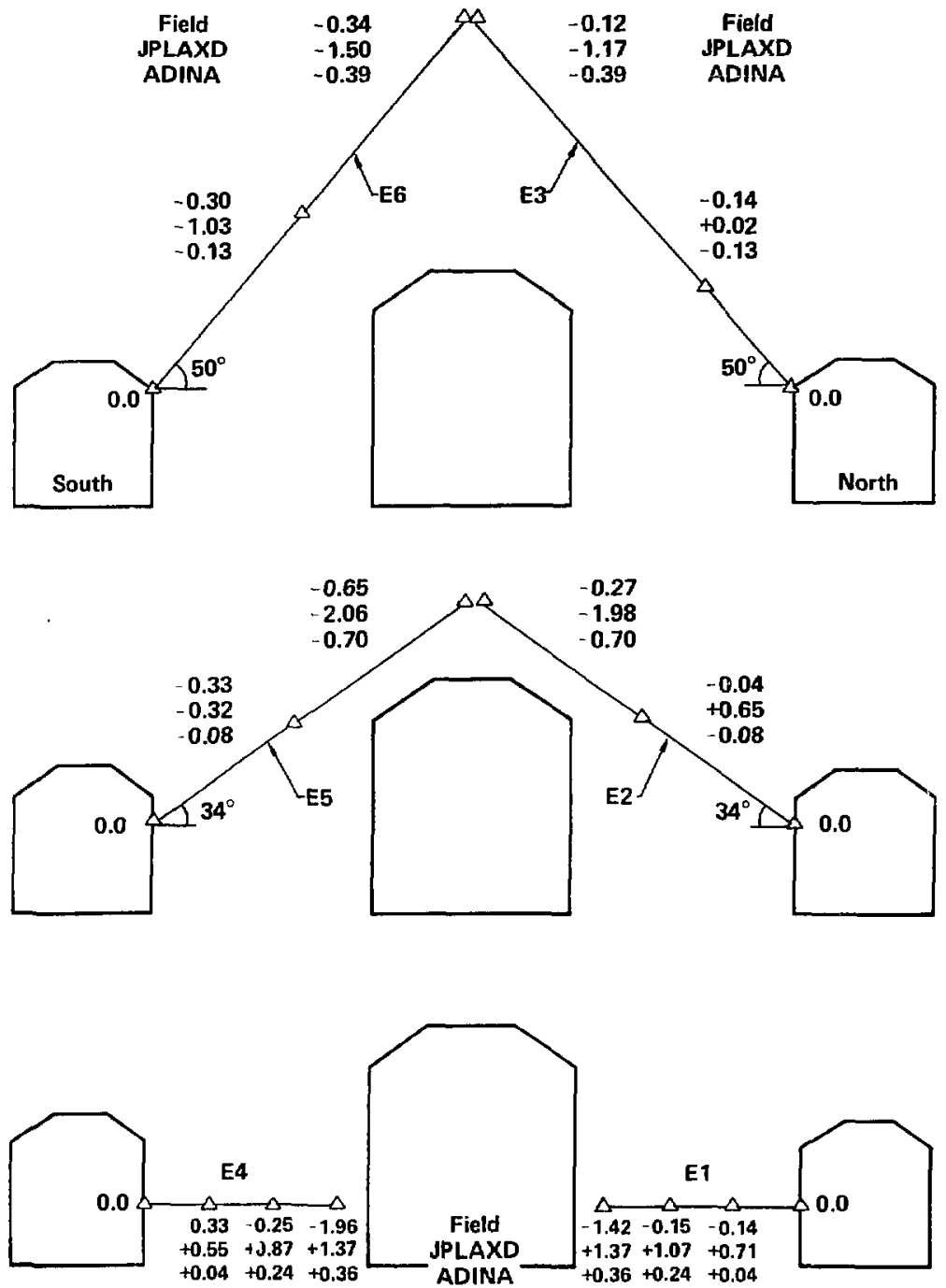

FIG. C-4. Conparison of field observations with JPLAXD and ADINR calculations for the relative movements of APE anchors during the mine-by (Inm) . Station $2+83$, dilatant joints. 

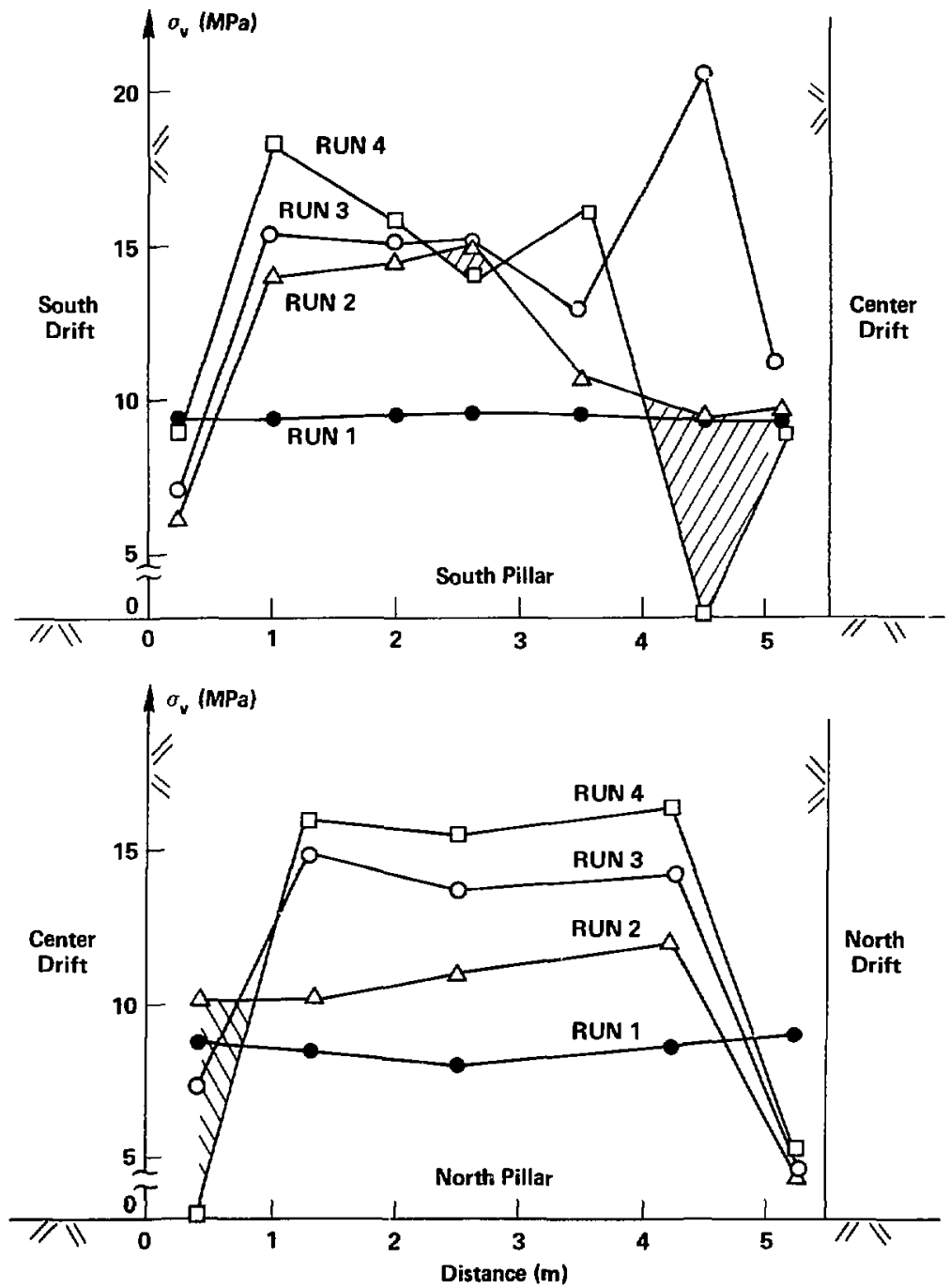

FIG. C-5. JPLAXD-calculated variation of vertical pillar stresses during the complete mining sequence. Hatching indicates a stress decrease during the mine-by. Station $2+83$, dilatant joints. 

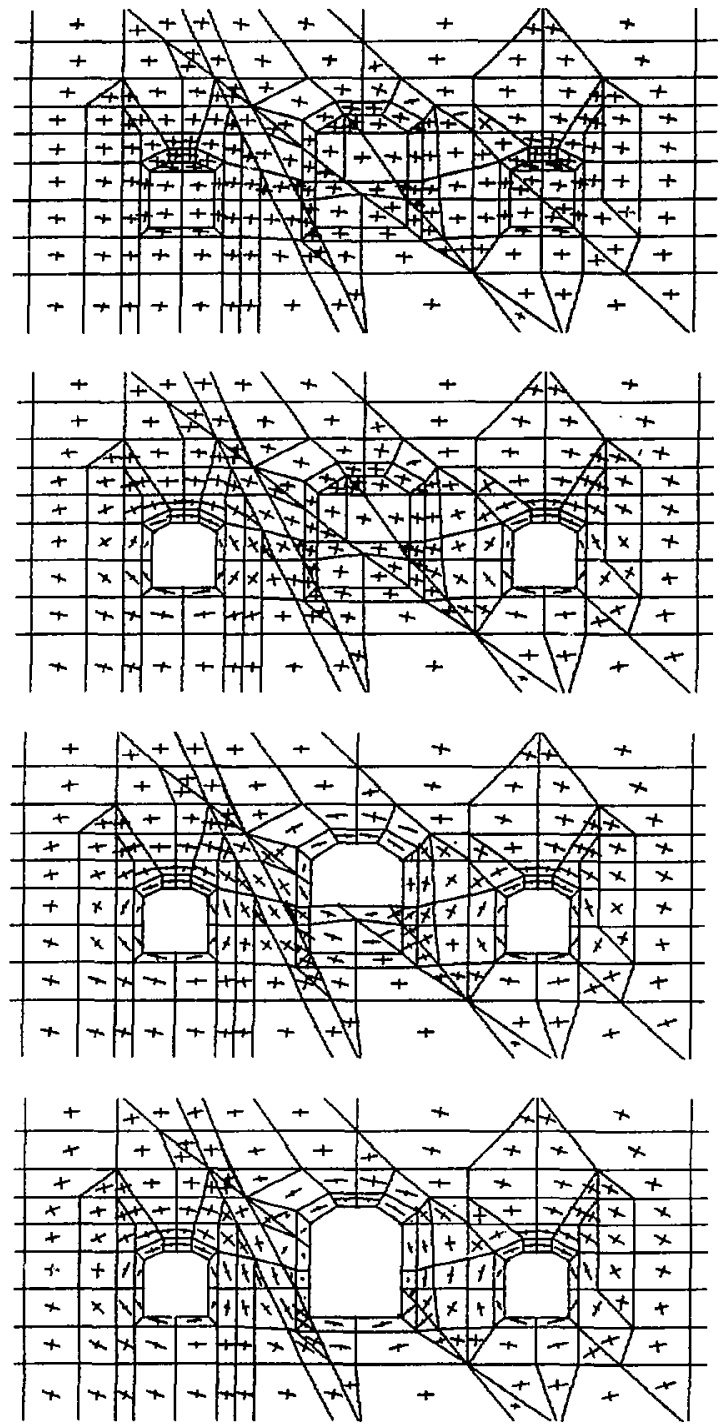

FIG. C-6. JPLAXD principal stress plots for the complete mining sequence. Station $2+83$, dilatant joints. 

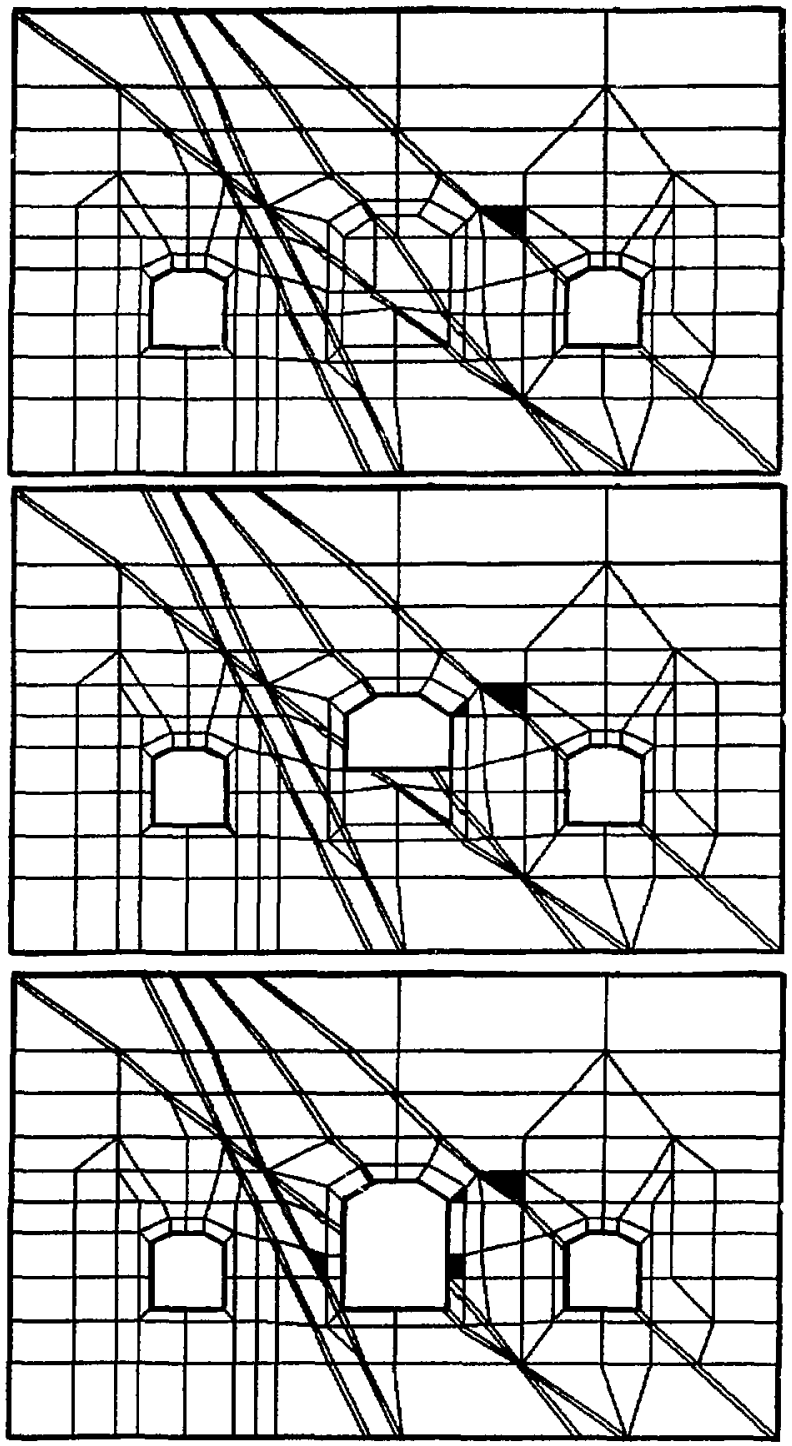

EIG. C-7. JPLAXD-calculated rock and joint failures in the mining sequence. Station $2+83$, dilatant joints. 
APPENDIX D.

Detailed Results from the Jointed Models:

Station $3+45$, Non-Dilatant Joints
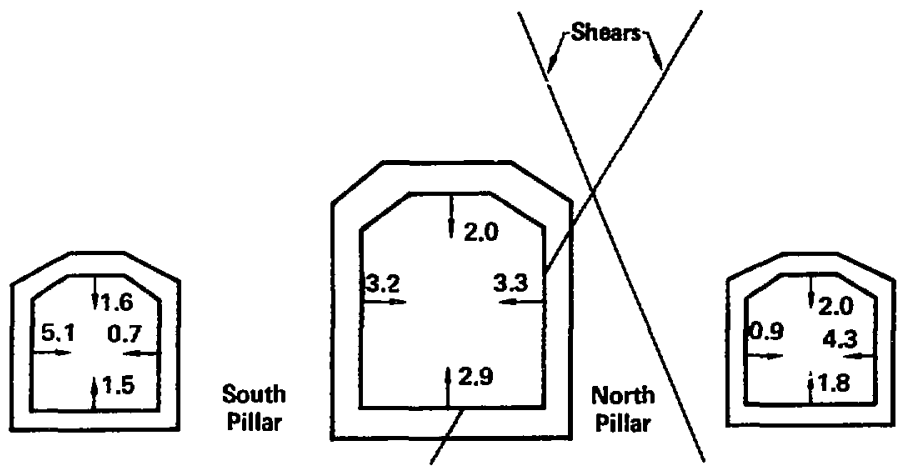

FIG. D-1. IPIAXD-calculated cavern closures (mi) for the complete mining stquence. Station $3+45$, non-dilatant joints.
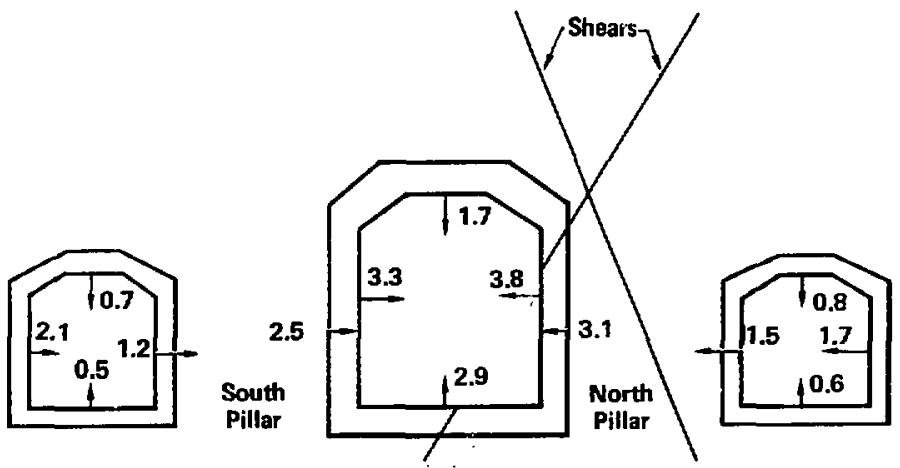

FIG. D-2. JPLAXD-calculated cavern closures (mm) for the mine-by of the center drift. Station $3+45$ non-dilatant joints. 


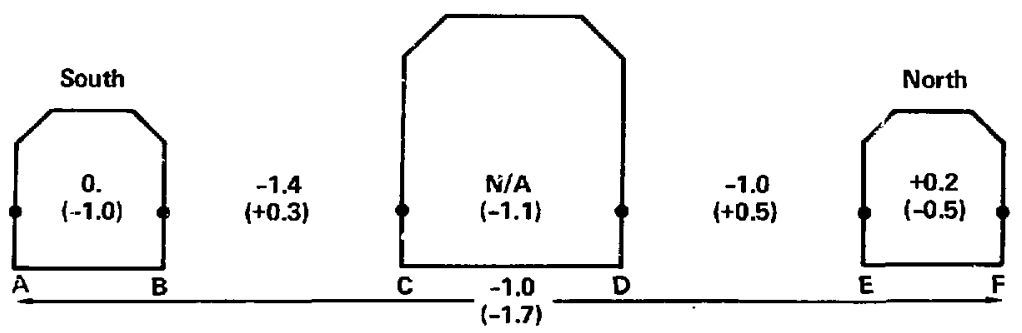

Top heading only
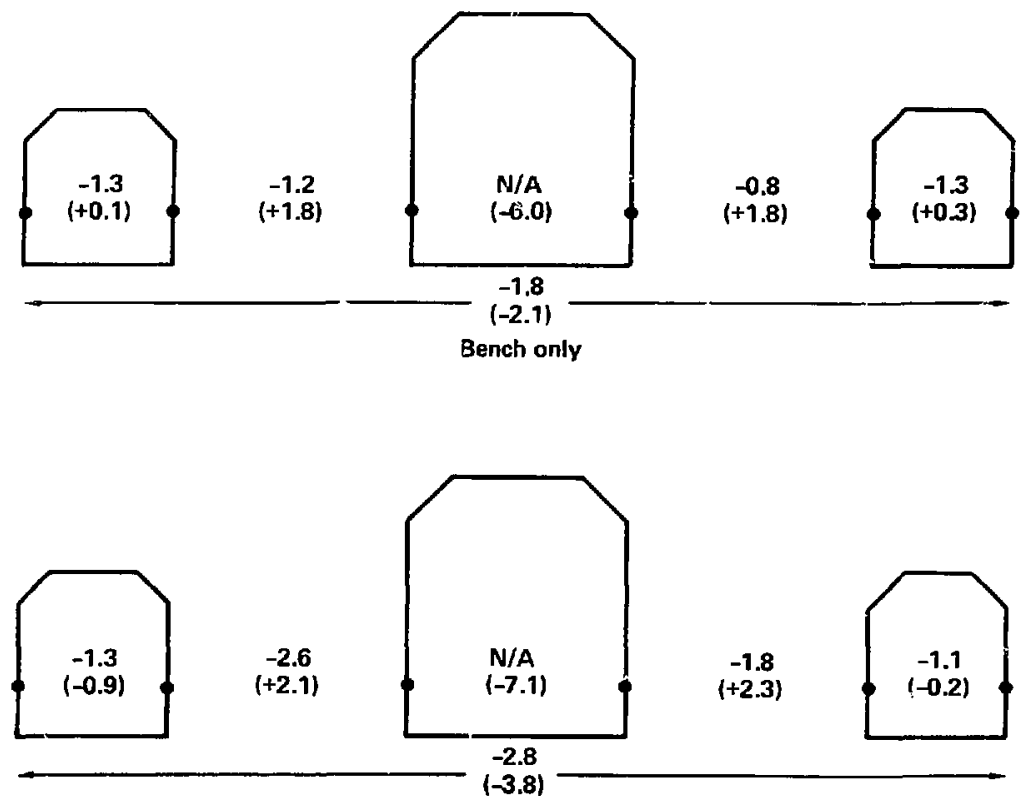

Top heading + bench

FIG. D-3. Comparison of field observations with (JPLAXD calculations) for the hor izontal movements across the three caverns, during mine-by (mm). Station $3+45$. 

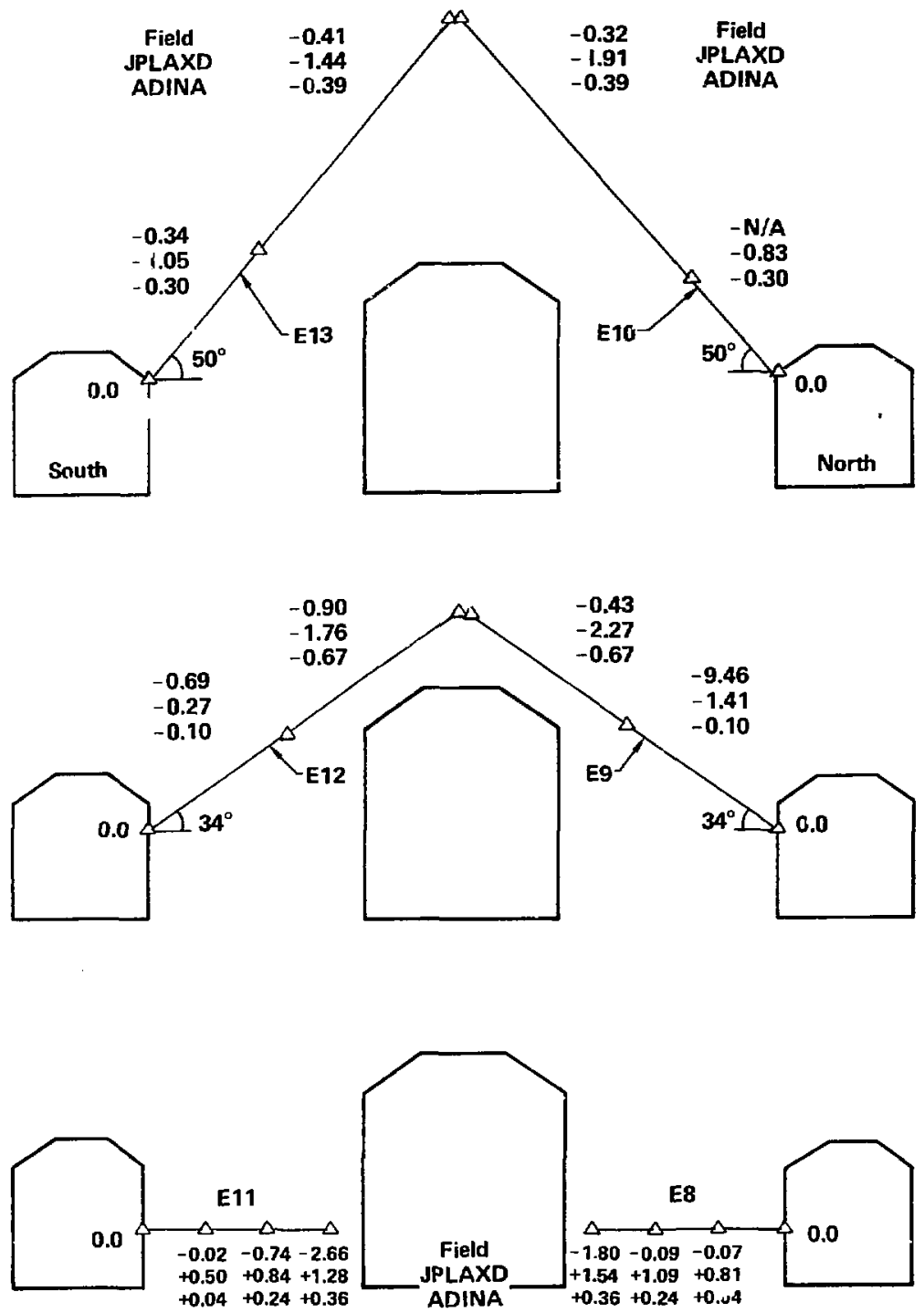

FIG. D-4. Comparison of field observations with JPIAXD and ADINA calculations for the relative movements of MPE anchors diring the mine-by (mm). 

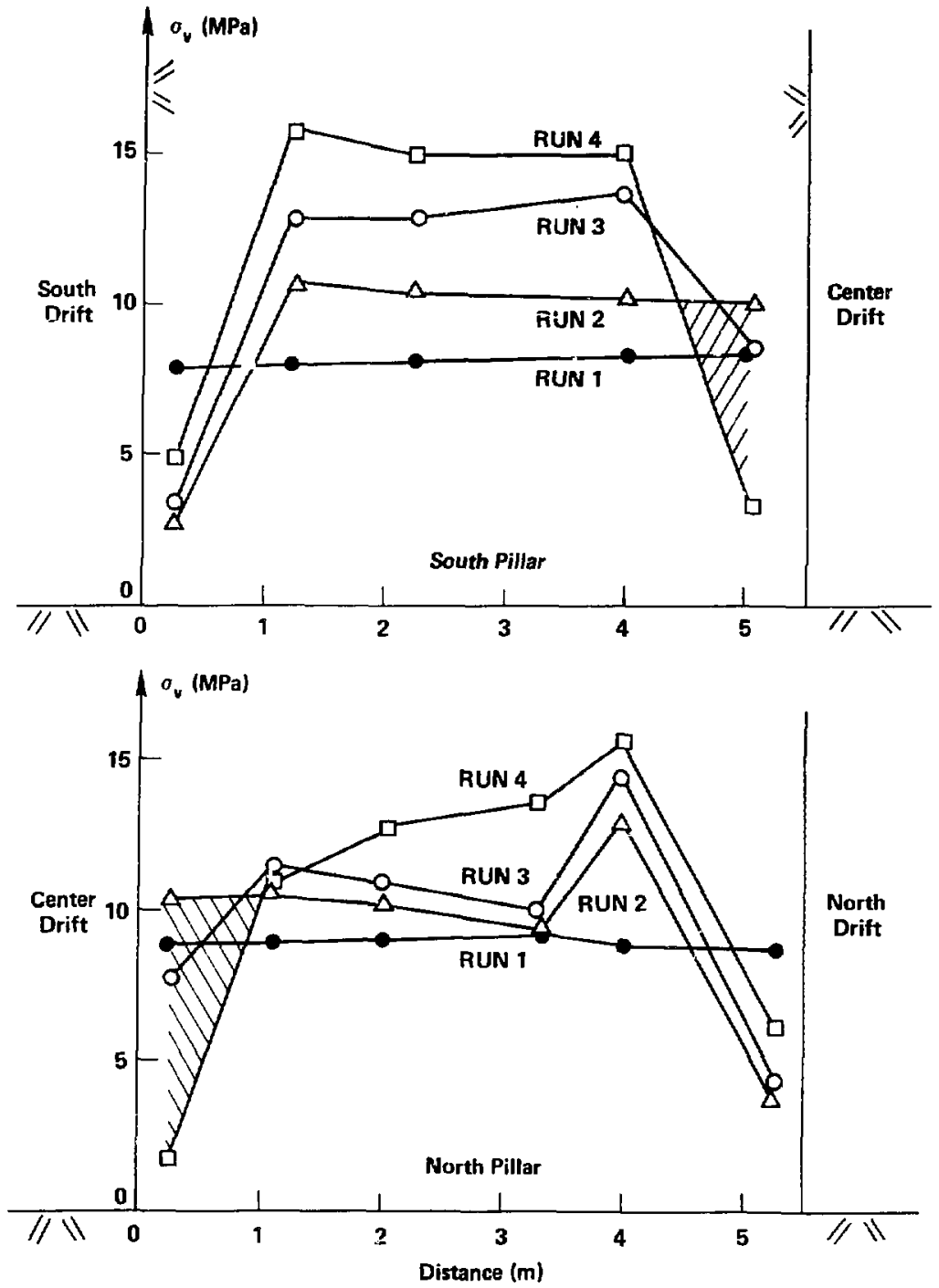

FIG. D-5. JPLAXD-calculated variation of vertical pillar stresses during the complete mining sequence. Hatching indicates a stress decrease during the mine-by. Station $3+45$, non-dilatant joints. 

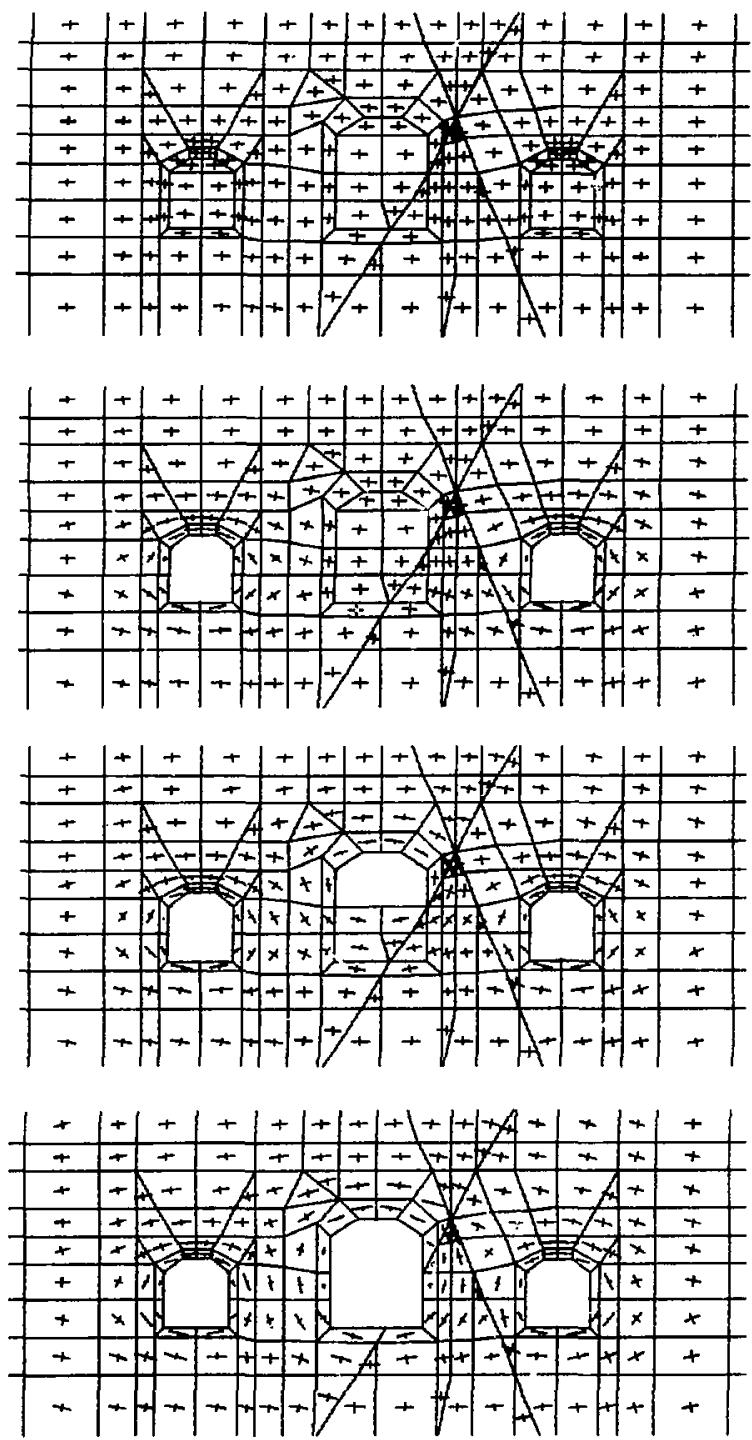

FIG. D-6. JPLAXD principal stress plots for the complete mining sequence. Station $3+45$, non-dilatant joints. 

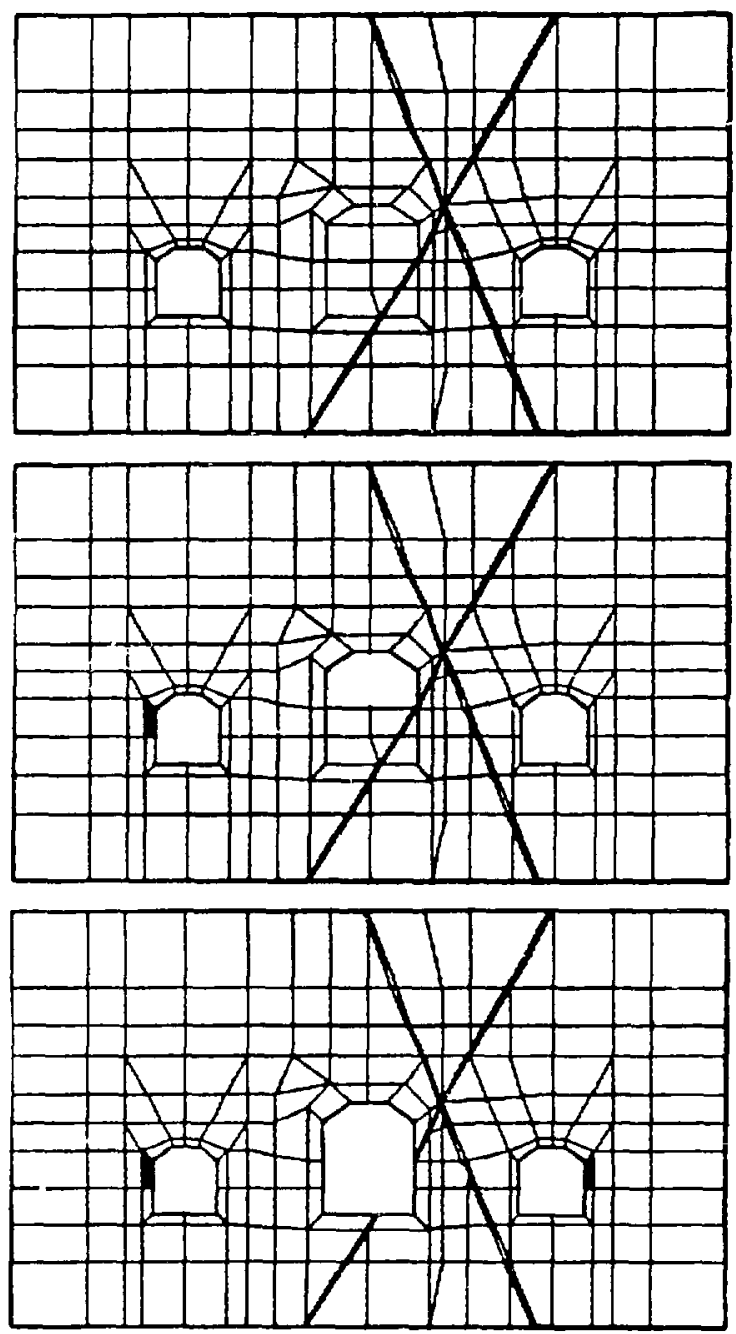

EIG. D-7. JPLAXD-calculated rock and join: failures in the mining sequence. station $3+45$, non-dilatant joints. 